\title{
Plasma cholinesterase is associated with Chinese adolescent overweight or obesity and metabolic syndrome prediction
}

This article was published in the following Dove Press journal: Diabetes, Metabolic Syndrome and Obesity: Targets and Therapy

\author{
Yanshuo Han ${ }^{1,2}$ \\ Yanan $\mathrm{Ma}^{\mathrm{l}, 3}$ \\ Yang Liu' \\ Zhongyi Zhao' \\ Shihan Zhen' \\ Xuelian Yang' \\ Zhiyong $\mathrm{Xu}^{4}$ \\ Deliang Wen'
}

'Institute of Health Science, China Medical University, Shenyang, People's Republic of China; ${ }^{2}$ Department of General Surgery, Shengjing Hospital of China Medical University, Shenyang, People's Republic of China; ${ }^{3}$ Public Health Department, China Medical University, Shenyang, People's Republic of China; ${ }^{4}$ Educational Research Centre of Huanggu District, Shenyang, People's Republic of China
Correspondence: Deliang Wen Institute of Health Science, China Medical University, No.77 Puhe Road, Shenyang North New Area, Shenyang, People's Republic of China

Tel +860243131 3333

Email dlwen@cmu.edu.cn
Purpose: To determine the plasma concentrations of butyrylcholinesterase (BChE), also known as pseudocholinesterase, in different weight categories of adolescents, and to explore the possible association between plasma $\mathrm{BChE}$ and overweight $(\mathrm{OW})$, obesity, and metabolic syndrome (MetS) in Chinese adolescents.

Patients and methods: This cross-sectional study included 1,236 Chinese adolescents (194 obese [OB], 188 OW, 732 normal weight [NW], and 122 underweight [UW]). The biochemical variables and anthropometric variables of the study participants were evaluated. Plasma BChE level was measured by DGKC method.

Results: OB was associated with a higher prevalence of upper strata plasma BChE levels when compared with the $\mathrm{BChE}$ levels in $\mathrm{UW}, \mathrm{NW}$, and $\mathrm{OW}$ group. A logistic regression analysis showed that plasma BChE was positively associated with the OB group when compared with the NW group. Boys in the OW group, but not the OB group, had a significantly higher prevalence of upper stratum of BChE levels. Plasma triglyceride, total cholesterol, low-density lipoprotein-cholesterol, and ApoB levels were positively associated with the upper stratum of BChE levels when compared with lower stratum. MetS and most of its components were more prevalent among subjects with upper stratum rather than lower stratum BChE levels. Receiver operating characteristic curves for plasma BChE in subjects with MetS indicated that the AUC was 0.80 (95\%CI:0.70-0.90,P<0.001) and 0.89 $(95 \% \mathrm{CI}: 0.82-0.95, P<0.001)$ in girls and boys, respectively. After adjusting for age, the multivariate-adjusted odds ratio for MetS in the upper stratum of BChE levels was 8.73 (95\%CI: 3.49-21.84) in the boys cohorts and also in the girls cohorts $(\mathrm{OR}=1.71,95 \% \mathrm{CI}$ : 1.35-21.70).

Conclusion: This study confirmed an association between BChE levels and weight status in Chinese adolescents, and demonstrated that the upper strata of plasma BChE levels were associated with being OW, and even more highly associated with obesity. Plasma BChE levels were positively associated with MetS and its components and could be useful for identifying adolescents with MetS.

Keywords: butyrylcholinesterase (BChE), adolescents obesity, metabolic syndrome, dyslipidemia

\section{Introduction}

The prevalence of childhood overweight (OW) or obesity has increased worldwide, and now represents a major public health crisis with economic consequences and substantial associated health care costs. ${ }^{1-3}$ Moreover, childhood obesity is associated with an increased incidence of comorbidities such as insulin resistance, diabetes 
mellitus, hypertension, sleep apnea, and cardiovascular disease, ${ }^{4-6}$ which give rise to increases in both direct and indirect costs. ${ }^{7}$ Recently, the NCD Risk Factor Collaboration pooled and analyzed population-based data concerning worldwide trends in pediatric obesity from 1975 through 2016, and found that increases in the body mass index (BMI) of children and adolescents had plateaued in highincome countries, while some Asian countries continued to have high rates of childhood and adolescent obesity. Moreover, these trends no longer correlated with those of adults. ${ }^{8}$ For all these reasons, there is an urgent need to avoid obesity during childhood and identify OW and obese (OB) children at an early age, so they can begin an effective intervention and maintain a healthy weight. The adipose tissue of OBchildren and adolescents not only stores lipids, but also releases large amounts of adipocytokines. ${ }^{9}$ Overproduction of adipocytokines can increase insulin resistance and blood pressure, cause oxidative stress, and disrupt normal lipid metabolism.

Metabolic syndrome (MetS) is defined as a group of risk factors for type II diabetes mellitus and cardiovascular disease, which include hypertension, abdominal obesity, glucose intolerance, and disorders of lipid metabolism. As a result of the ongoing obesity epidemic among adolescents and children, MetS has also become important public health in that population. ${ }^{10,11}$ Therefore, biomarkers that can predict the risk for developing metabolism syndrome in adolescents or pediatric populations are critical for better management of this syndrome.

Cholinesterase (ChE) belongs to a group of enzymes that hydrolyze acetylcholine and other choline esters. Human tissues have two different types of $\mathrm{ChE}$ enzymes: ${ }^{12}$ acetylcholinesterase (AChE) and butyrylcholinesterase $(\mathrm{BChE})$. AChE is present in the central nervous system and skeletal muscles and located in the erythrocyte membrane, while BChE (also known as pseudocholinesterase) is synthesized in the liver and secreted into plasma. The main function of $\mathrm{AChE}$ is to hydrolyze acetylcholine at the cholinergic synapse. The function of $\mathrm{BChE}$ is unclear, but it may be involved in the growth or detoxification of body tissues. $^{13,14}$ The substrate specificity of $\mathrm{ChE}$ enzymes is highly dependent on the structure of the acyl binding pocket, as defined by the phenylalanine residue located at the bottom of the ChE catalyst valley. ${ }^{15,16}$ The physiological function of $\mathrm{BChE}$ has remained unclear; however, several studies have suggested that BChE participates in myelin maintenance, cellular adhesion, and neurogenesis, and serves as a scavenger of toxic molecules. ${ }^{17,18}$ Current studies investigating the activity of $\mathrm{BChE}$ in humans have enrolled adult patients with the hepatobiliary disease, ${ }^{19}$ hyperlipidemia, ${ }^{20}$ diabetes, ${ }^{21}$ or cardiovascular disease. ${ }^{22}$ However, few studies have investigated changes that occur in BChE activity in OB adults or those with MetS. ${ }^{23}$

Although several recent studies have reported increased levels of BChE in the plasma of individuals with abdominal obesity $^{23}$ and MetS, ${ }^{24}$ less studies have investigated the relationship between obesity in a general adolescent population and plasma $\mathrm{BChE}$ concentrations. Moreover, it remains uncertain whether improved BChE levels would be beneficial to adolescents with MetS; however, that topic has recently received increased attention. While high levels of BChE have been associated with obesity in a variety of populations, this association has not been confirmed in Chinese adolescents' populations, and is the primary aim of this study. We also assessed the relationship between BChE concentrations and several components of MetS.

\section{Material and methods Study design}

This study was conducted in the city of Shenyang, China, and individuals attending state-funded or private primary and middle schools in traditional urban districts of Shenyang were eligible for inclusion. Our investigation used screening data obtained from a Huanggu District Middle and Primary School Student Physical Fitness Monitoring (HMPSPM) database for the years 2017-2018. The database was created to help investigate the health outcomes, weight status, and growth status of primary and middle-school children and adolescents in northeast China, as previously described. ${ }^{25}$ In this research, a cross-sectional school-based survey of 13-19-year-old adolescents $(n=1559)$ was conducted in five middle schools in the Huanggu District in Shenyang City, China, from September 2017 to April 2018. Anthropometric measurements and blood sample data were collected. All eligible participants and their parent(s) signed an Informed Consent agreement prior to participating in the study. The study protocol was approved by the Ethics Committee of the Institute of Health Science (Ethics Approval No. [2017] 055), China Medical University (CMU), and all study procedures were performed in accordance with the Declaration of Helsinki.

\section{School and participant recruitment}

The city of Shenyang is administratively divided into three rural districts and ten urban districts, and this study was 
conducted only in the Huanggu urban district, and only schools located in the Huanggu District of Shenyang City were selected for participation. Each participating school had a different schedule for administering physical examinations; therefore, this study used a two-phase physical examination and blood sample collection approach. In the Phase (I), four middle schools were randomly selected from the Huanggu District in Shenyang City during September or October of 2017. In the Phase (II), April 2018, another middle school was selected from the list of all primary schools in the Huanggu District. The selected schools were invited to participate in our study via a written invitation from the Primary and Secondary School Healthy Care Center of Huanggu District and followed by telephone calls. Visits were made to explain the purpose of the study, confirm participation, and obtain a signed written Informed Consent document from each school's principal. Student birth dates were obtained from the school's registration form in order to confirm the adolescent's age. If selected schools enroll less than 100 students were excluded in this study. Students who were older than 18 years, who had a severe systemic disease or intellectual impairment were also excluded in this research from participation.

\section{Study population}

From September 2017 to April 2018, our study initially enrolled 1,559 Chinese adolescent students in grades 7-12 from five public or private middle schools in Shenyang, China. After anthropometry measurements and blood sample analyses were completed, a total of 1,236 adolescent students (age 13-18 years) remained eligible to participate. A flowchart showing the participant selection process is provided in Figure 1.

\section{Anthropometric measurements}

A single researcher performed all anthropometric measurements in accordance with World Health Organization standards. Student heights were measured to the nearest $0.1 \mathrm{~cm}$ using a portable stadiometer (SECA 213, Hamburg, Germany), and weights were measured in kilograms using a body fat analyzer (TANITA DC430MA, Tokyo, Japan). BMI was calculated as weight in kilograms divided by height in meters squared $\left(\mathrm{kg} / \mathrm{m}^{2}\right)$. Z-scores were assigned to represent the standard deviation of each individual's BMI from the average value for age and gender-matched population according to Chinese reference values for different ages and genders. Hip and waist circumference were measured by established techniques, ${ }^{26}$ and waist-to-height and waist-to-hip ratios (WHtR and WHR) were calculated as waist circumference $(\mathrm{cm})$ divided by height $(\mathrm{cm})$ and hip circumference $(\mathrm{cm})$, respectively. The body adiposity index (BAI) ${ }^{27}$ was calculated as BAI $=\left(\right.$ hip circumference $[\mathrm{cm}] /$ height $\left.[\mathrm{m}]^{1.5}\right)-18$. Blood pressure was measured with an Omron i-C10 blood pressure monitor (Omron Healthcare Co., Ltd, Kyoto, Japan), and arterial hypertension was defined according to existing recommendations. ${ }^{28}$

\section{Blood sample collection}

Venipuncture was performed with the written informed consent of each participant and their parents, who were aware of the intended use of the samples. The Ethics Committee of the Institute of Health Science, China Medical University (CMU) approved the venous blood collection protocol, which was performed in accordance with the Declaration of Helsinki. Venipuncture was performed after a 12-hr fast, and specimens were collected in EDTA plastic tubes (BD Vacutainer ${ }^{\circledR}$ lavender, $5.0 \mathrm{~mL}$ ) or anticoagulant and silica/gel plastic tubes (SST BD Vacutainer® gold, $5.0 \mathrm{~mL}$ ). Plasma was obtained by centrifugation and could be stored for up to six months at $-80^{\circ} \mathrm{C}$ for further analysis.

\section{Laboratory examinations}

All adolescent blood tests were conducted by the Department of Clinical Laboratory, Shengjing Hospital of CMU. The blood test results for each student were provided to the corresponding middle school. When abnormal results were obtained, the student was notified and encouraged to have a second blood test performed after a 1-month interval or visit an outpatient clinic.

Hepatic panel. ALT, AST, ALP, and GGT levels were measured by using an International Federation of Clinical Chemistry method (Abbott Laboratories, North Chicago, IL, USA). Plasma BChE was measured according to the recommendation by DGKC which is a kinetic method and Cholinesterase Assay Kit (Beijing Strong Biotechnologies, Inc, China), which uses Colorimetic Butrylthiocholine as a substrate. ${ }^{29}$ Total bile acid was measured by the butyryl glucosinolates choline substrate method and enzymatic cycling method, respectively (Beijing Strong Biotechnologies, Inc, China). Total protein, albumin (Alb), total bilirubin (TBil), and conjugated bilirubin (CB) concentrations were determined by the biuret method, the BCG method, and the vanadic acid oxidation 


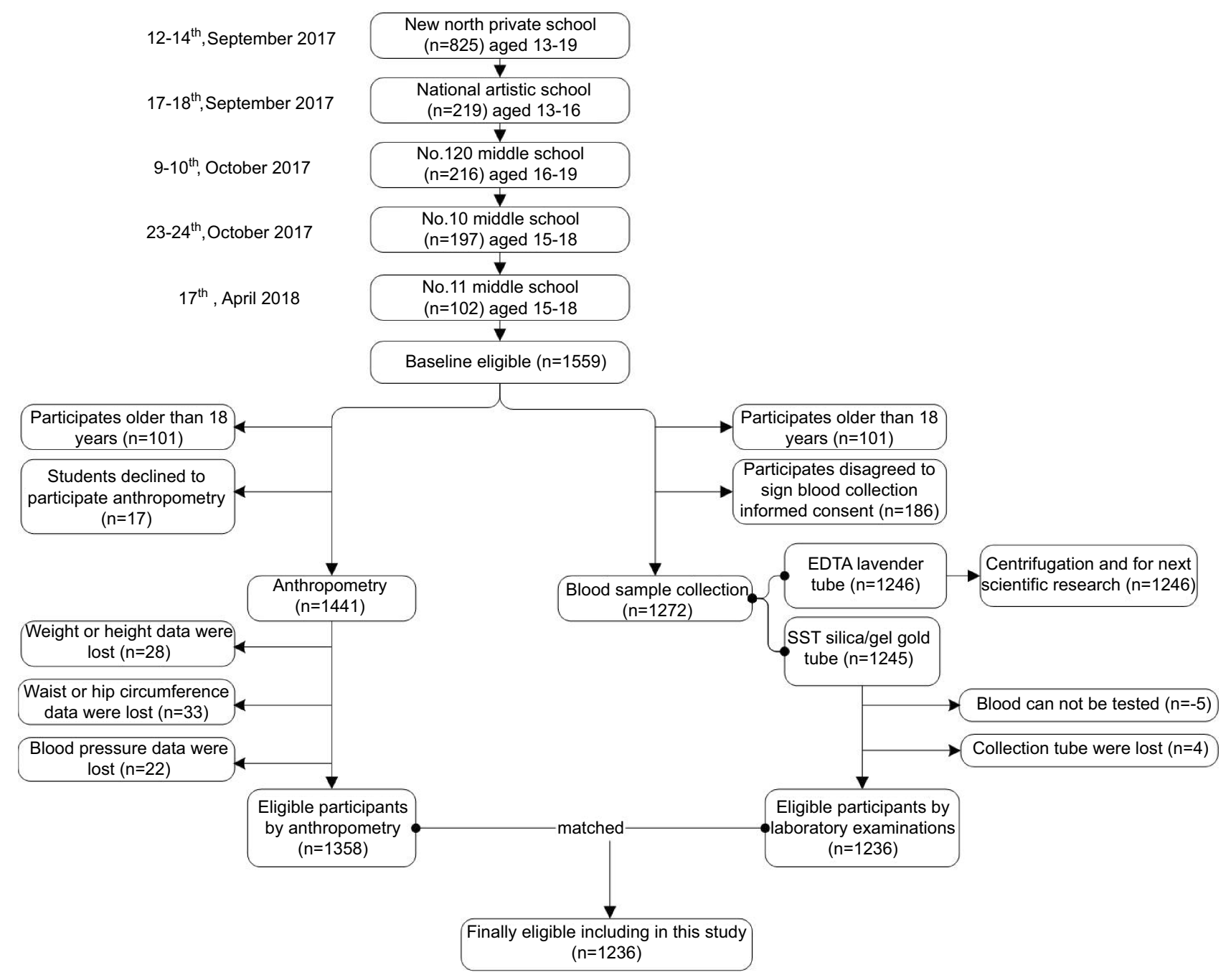

Figure I The northeast of Chinese adolescents participant flow.

method, respectively (FUJIFILM Wako Pure Chemical industries Ltd, Japan). Pre-albumin (PA1) was measured by immunoturbidimetric method (Prealbumin FS, ERM®DA470k/IFCC, DiaSys Diagnostic Systems GmbH, Germany).

Lipid panel. The selective solubilization method (Lowdensity lipid cholesterol test Kit or Determiner L HDL, Kyowa Medex, Tokyo) was used to directly analyze the plasma levels of low-density lipoprotein-cholesterol (LDL-C) and high-density lipoprotein-cholesterol (HDL$\mathrm{C}$ ), and enzymatic methods were used to measure total cholesterol (TC) and triglyceride (TG) levels. ApoA1 and ApoB levels were measured using immunoturbidimetric method (Kits for BioMajesty ${ }^{\circledR}$ JCA-BM6010/C, DiaSys Diagnostic Systems GmbH, Germany). The lipid profiles were generated by an automatic biochemistry analyzer (ARCHIRECT ci16200, Abbott Laboratories, USA).

\section{Definition of clinical variables} Definition of adolescent OW and obesity

OW and obesity were defined by BMI in accordance with recommendations made by the Working Group on Obesity in China (WGOC) ${ }^{30}$ as: $\geq 28$, OB; $24.0-27.9$, OW; $18.5-$ 23.9, normal weight $(\mathrm{NW}) ;<18.5$, underweight (UW). According to the 2005 WGOC standard, a BMI of 24 was the cut-off point for $\mathrm{OB}$ vs OW. ${ }^{31}$

\section{Definition of MetS}

MetS was diagnosed in accordance with the International Diabetes Federation (IDF) consensus report on MetS in adolescents population. ${ }^{32}$ In children aged from 6 to 10 years, MetS cannot be diagnosed, but further measurements should be made if there is a family history of MetS or type 2 diabetes mellitus (T2DM). In this research, a school-based survey of 13-19-year-old adolescents was 
conducted. Therefore, MetS is diagnosed when central obesity plus any two of the other four factors: (1) a TG level $\geq 150 \mathrm{mg} / \mathrm{dL}$; (2) an HDL-C level $<40 \mathrm{mg} / \mathrm{dL}$ for boys of all ages and girls aged $<16$ years, and an HDL-C level $<50 \mathrm{mg} / \mathrm{dL}$ for girls aged $\geq 16$ years; (3) A systolic blood pressure (BPS) $\geq 130 \mathrm{mmHg}$ or diastolic blood pressure (BPD) $\geq 85 \mathrm{mmHg}$; (4) a fast plasma glucose (FPG) level more than $5.6 \mathrm{mmol} / \mathrm{L}$ or known T2DM. Central obesity is defined as a waist circumference at or above the 90th percentile for age and gender in children under the age of 16 , and as a waist circumference $\geq 90 \mathrm{~cm}$ (male) or $\geq 80 \mathrm{~cm}$ (female) after age 16 .

\section{Definition of cholinesterase (BChE) stratum}

The upper and lower strata of $\mathrm{BChE}$ levels were defined according to the cut-off values for the 75 th percentile, ${ }^{33}$ which in the present study were $8481.0 \mathrm{U} / \mathrm{L}$ for girls and 9083.3U/L for boys.

\section{Statistical analysis}

SPSS 22.0 (SPSS Inc., Chicago, IL, USA) was used for statistical analysis. And a $P$-value $<0.05$ was considered statistically significant.

Because of the non-Gaussian data distribution in this study, data for continuous variables are expressed as medians with upper or lower quartiles. Kruskal-Wallis one-way analysis of variance by rank test and the nonparametric Mann-Whitney test were used to analyze differences among more than two groups and differences between two groups, respectively. Categorical data are expressed as numbers with percentages. The chi-square test was used to examine the differences between the two groups in terms of biochemical and clinical parameters.

Multiple logistic regression analyses were performed by first carrying out multiple linear and logistic regression analyses adjusted for confounding factors, including gender and age, to examine the association between $\mathrm{BChE}$ and adolescent weight status. Standardized regression coefficients and odds ratios (ORs) with $95 \%$ confident intervals (95\%CIs) are presented with adjustments made for potential confounding factors. Additionally, receiver operating characteristic (ROC) curves of plasma $\mathrm{BChE}$ for the diagnosis of adolescent's metabolism syndrome were used to evaluate the clinical utility of performing $\mathrm{BChE}$ concentration in predicting MetS in adolescents. Areas under the ROC curve (AUCs) were calculated for both girls and boys.

\section{Results}

\section{Baseline characteristics}

Table 1 shows the baseline characteristics of the study participants. The participants were classified according to weight status as OB ( $\mathrm{n}=194,85$ girls and 109 boys); OW ( $\mathrm{n}=188,91$ girls and 97 boys); NW ( $\mathrm{n}=732,379$ girls and 353 boys); or UW ( $\mathrm{n}=122,60$ girls and 62 boys). In the whole cohorts, the prevalence of upper strata $\mathrm{BChE}$ levels was markedly higher in the $\mathrm{OB}$ group than in the other groups. The prevalence of MetS in the OB group was $30.4 \%$ and, in OW group adolescents, it was $5.3 \%$. The direct associations of anthropometry, blood biochemical parameters, and $\mathrm{BChE}$ concentrations with gender are presented in Table S1. In the girls' cohorts, the prevalence of upper strata BChE levels was markedly higher in the OB group than in the other groups as well as the boys' cohorts.

\section{Association of each lipid biomarker with an adolescent's weight status}

Direct associations between the levels of various plasma lipid biomarkers the BMI values of adolescents are shown in Table 2. The levels of circulating TG, TC, LDL-C, and apolipoprotein $\mathrm{B}(\mathrm{ApoB})$ were all positively associated with the BMI values of adolescents (all $P$-values $<0.001$ ). A multiple logistic regression analysis showed that when compared with the NW groups, all six classical indices (ie, TG, TC, HDL-C, LDL-C, ApoA1, and ApoB) were predictive for both $\mathrm{OB}$ and $\mathrm{OW}+\mathrm{OB}$, and that HDL-C, LDLC, ApoA1, and ApoB were predictive for OW (Table 3).

\section{Association of each liver enzyme biomarker with an adolescent's weight status}

The associations between liver enzyme biomarker levels and the BMI values of adolescents are shown in Table 2 . Interestingly, serum or plasma ALT, AST, ALP, GGT, and BChE levels were positively associated with the BMI values of adolescents (ALT: $P<0.001$, AST: $P<0.001$, ALP: $P<0.001$, GGT: $P=0.011$ and BChE: $P<0.001$ ). A multiple logistic regression analysis showed that plasma ALT, AST, GGT, and BChE levels were positively associated with both the $\mathrm{OB}$ group and $\mathrm{OW}+\mathrm{OB}$ group when compared with the NW group (Table 3). For example, the adjusted ORs of $\mathrm{BChE}$ increased from $1.31(95 \% \mathrm{CI}$ : $1.10-1.55, p=0.002)$ at an OW status to $2.44(95 \% \mathrm{CI}$ : $1.97-3.02, P<0.001)$ at an $\mathrm{OB}$ status. 
Table I Characteristics of the study population

\begin{tabular}{|c|c|c|c|c|c|}
\hline Parameter & $\begin{array}{l}\text { UW, median } \\
\text { (lower; upper } \\
\text { quartiles) }\end{array}$ & $\begin{array}{l}\text { NW, median } \\
\text { (lower; upper } \\
\text { quartiles) }\end{array}$ & $\begin{array}{l}\text { OW, median } \\
\text { (lower; upper } \\
\text { quartiles) }\end{array}$ & $\begin{array}{l}\text { OB, median } \\
\text { (lower; upper } \\
\text { quartiles) }\end{array}$ & $P$-value \\
\hline Body height $(\mathrm{cm})$ & $1.70(1.64 ; 1.73)$ & $1.67(1.61 ; 1.73)$ & $1.66(1.60 ; 1.73)$ & $1.70(1.64 ; 1.77)$ & E \\
\hline Body weight (kg) & 44.50 (4I.70; 48.28) & $55.80(50.70 ; 61.01)$ & $70.30(65.05 ; 76.30)$ & 91.10 (82.30; 102.65) & A-F \\
\hline Waist circumference $(\mathrm{cm})$ & $63.50(60 ; 67.25)$ & $69.00(65.00 ; 73.00)$ & $80(75 ; 84)$ & $93.5(87.38 ; 100)$ & A-F \\
\hline Hip circumference $(\mathrm{cm})$ & $84(82.75 ; 86.25)$ & 91 (88; 94) & $100(97 ; 103)$ & $110(107 ; 115)$ & A-F \\
\hline BMI (kg m-2) & $15.74(15.36 ; 16.2)$ & $20.22(18.74 ; 21.56)$ & $25.48(24.58 ; 26.75)$ & $31.37(29.49 ; 33.85)$ & A-F \\
\hline BMI z-score & $-1.43(-1.51 ;-1.33)$ & $-0.49(-0.8 ;-0.21)$ & $0.62(0.43 ; 0.88)$ & $1.85(1.46 ; 2.37)$ & A-F \\
\hline Body weight z-score & $-1.2(-1.38 ;-0.96)$ & $-0.48(-0.8 ;-0.14)$ & $0.46(0.12 ; 0.84)$ & $1.8(1.23 ; 2.54)$ & A-F \\
\hline $\begin{array}{l}\text { Waist circumference } \\
\text { z-score }\end{array}$ & $-0.97(-1.29 ;-0.63)$ & $-0.46(-0.83 ;-0.1)$ & $0.55(0.09 ; 0.91)$ & $1.79(1.23 ; 2.39)$ & A-F \\
\hline Hip circumference z-score & $-1.23(-1.37 ;-0.97)$ & $-0.44(-0.78 ;-0.09)$ & $0.59(0.25 ; 0.93)$ & $1.72(1.38 ; 2.29)$ & A-F \\
\hline WHtR & $0.38(0.36 ; 0.39)$ & $0.4 \mathrm{I}(0.39 ; 0.43)$ & $0.48(0.46 ; 0.5)$ & $0.55(0.52 ; 0.58)$ & A-F \\
\hline WHR & $0.75(0.7 \mathrm{I} ; 0.8 \mathrm{I})$ & $0.76(0.73 ; 0.78)$ & $0.8(0.77 ; 0.83)$ & $0.85(0.8 \mathrm{I} ; 0.89)$ & $B-F$ \\
\hline BPS $(\mathrm{mm} \mathrm{Hg})$ & II $6.5(109.75 ; 121.25)$ & $115(107 ; 123)$ & $122(113 ; 133)$ & $131.5(124 ; 144.25)$ & $B-F$ \\
\hline $\mathrm{BPD}(\mathrm{mmHg})$ & $70(60.5 ; 78.25)$ & $65(60 ; 70)$ & $67(61 ; 73)$ & $71.5(65 ; 77.25)$ & $\mathrm{D}, \mathrm{E}$ \\
\hline Pulse rate & $85(76.5 ; 96.25)$ & $85(75 ; 92)$ & $85(77 ; 92.5)$ & $86(76.75 ; 96)$ & NS \\
\hline TP $(g / L)$ & $78(76.58 ; 83.05)$ & 79.9 (77; 82.9) & $79.9(76.9 ; 82.75)$ & $80(77.2 ; 83.03)$ & NS \\
\hline Albumin, Alb (g/L) & $50.65(48.78 ; 53.65)$ & $50.8(48.9 ; 52.7)$ & $50.3(48.65 ; 52.3)$ & $49.7(47.7 ; 52.03)$ & $\mathrm{C}, \mathrm{E}$ \\
\hline ALT (U/L) & $9.5(7.75 ; \mathrm{II})$ & $10(8 ; 13)$ & $13(9 ; 19)$ & $25(14 ; 39.25)$ & A-F \\
\hline AST (U/L) & $14(13 ; 15.25)$ & $15(13 ; 17)$ & $16(13 ; 19)$ & $19(15 ; 25)$ & C, E, F \\
\hline ALP (U/L) & I03.5 (70; I59.25) & $93(76 ; 121)$ & $93(75.5 ; 120.5)$ & IOI (8I.75; I26.75) & NS \\
\hline GGT (U/L) & $15(11.75 ; 16)$ & $15(12 ; 19)$ & $18(14 ; 26)$ & $26(19 ; 34.25)$ & B-F \\
\hline BChE (U/L) & $\begin{array}{l}7,351(6661.25 \\
7891.75)\end{array}$ & 7,709 (70|4.5; 8,478) & $8,350(7,610 ; 9217.5)$ & $\begin{array}{l}9294.5(8,463 ; \\
10,127.5)\end{array}$ & B-F \\
\hline PAI (g/L) & $0.24(0.21 ; 0.27)$ & $0.25(0.22 ; 0.28)$ & $0.25(0.22 ; 0.29)$ & $0.27(0.23 ; 0.29)$ & $\mathrm{C}, \mathrm{E}$ \\
\hline BilT (mmol/L) & $16.8(13.73 ; 22.9)$ & I3.3 (9.8; 17.3) & $12.8(9.8 ; 16.25)$ & $12.25(9.3 ; 16.23)$ & NS \\
\hline $\mathrm{CB}(\mathrm{mmol} / \mathrm{L})$ & $6.3(5.2 ; 8.25)$ & $5.3(3.8 ; 6.9)$ & $4.8(3.5 ; 6.6)$ & $4.65(3.5 ; 6.23)$ & NS \\
\hline UCB (mmol/L) & $10.7(7.93 ; 14.3)$ & $8.1(5.9 ; 10.55)$ & $7.7(6 ; 10)$ & $7.55(5.65 ; 10.1)$ & NS \\
\hline TBA (mmol/L) & $2.8(2 ; 4.38)$ & $2.4(1.4 ; 3.6)$ & $2(1.15 ; 3.2)$ & $2(1.3 ; 3.13)$ & $B, D$ \\
\hline FPG (mmol/L) & $4.3(3.87 ; 4.55)$ & $4.28(4 ; 4.56)$ & $4.28(3.99 ; 4.58)$ & $4.31(4 ; 4.64)$ & NS \\
\hline TG (mmol/L) & $0.67(0.53 ; 0.88)$ & $0.71(0.53 ; 0.96)$ & $0.81(0.58 ; 1.07)$ & $1.04(0.75 ; 1.44)$ & C, E, F \\
\hline $\mathrm{TC}(\mathrm{mmol} / \mathrm{L})$ & $3.9(3.43 ; 4.32)$ & $3.84(3.4 I ; 4.3)$ & $3.95(3.46 ; 4.45)$ & $4.25(3.82 ; 4.7)$ & $C, E, F$ \\
\hline HDL-C (mmol/L) & $1.42(1.12 ; 1.73)$ & $1.34(1.17 ; 1.54)$ & I.24 (I.I; I.47) & $1.13(0.99 ; 1.26)$ & B-E \\
\hline LDL-C (mmol/L) & $1.94(1.69 ; 2.53)$ & 2.05 (I.7I; 2.43) & $2.19(1.81 ; 2.55)$ & $2.54(2.16 ; 2.85)$ & $\mathrm{B}, \mathrm{C}, \mathrm{E}, \mathrm{F}$ \\
\hline ApoAI (g/L) & 1.39 (1.21; I.49) & $1.33(1.22 ; 1.46)$ & $1.26(1.16 ; 1.4)$ & $1.24(1.13 ; 1.34)$ & B-E \\
\hline ApoB $(g / L)$ & $0.58(0.49 ; 0.7)$ & $0.6(0.52 ; 0.7)$ & $0.66(0.56 ; 0.75)$ & $0.76(0.64 ; 0.86)$ & B-F \\
\hline MetS (n/N,\%) & $0 / 122(0.0 \%)$ & $2 / 732(0.3 \%)$ & $10 / 188$ (5.3\%) & $59 / 194$ (30.4\%) & B-F \\
\hline
\end{tabular}

Note: ${ }^{*} P=K$ Kuskal-Wallis multiple-comparison $Z$ value test. $P$-values $<0.05$ were considered statistically significant: $A=U W$ vs $N W, B=U W$ vs $O W, C=U W$ vs $O B, D=N W$ vs $\mathrm{OW}, \mathrm{E}=\mathrm{NW}$ vs $\mathrm{OB}, \mathrm{F}=\mathrm{OW}$ vs $\mathrm{OB}$.

Abbreviations: UW, underweight group; NW, normal weight group; OW, overweight group; OB, obese group; BMI, body mass index; WHR, waist-to-hip ratio; WHtR, waist-to-height ratio; BPS, systolic blood pressure; BPD, diastolic blood pressure; TP, total protein; ALT, alanine aminotransferase; AST, aspartate aminotransferase; ALP, alkaline phosphatase; GGT, gamma-glutamyl transpeptidase; PAI, pre-albumin; BilT, total bilirubin; CB, conjugated bilirubin; UCB, un-conjugated bilirubin; TBA, total bile acid; FPG, fasting plasma glucose; TG, triglycerides; TC, total cholesterol; HDL-C, high-density lipoprotein-cholesterol; LDL-C, low-density lipoprotein-cholesterol; ApoAI, apolipoprotein AI; AopB, apolipoprotein B.

\section{The stratum of BChE according to weight} categories and gender

The prevalence of upper stratum BChE levels was $17.8 \%$ in the UW group, $16.0 \%$ in the NW group, $31.1 \%$ in the OW group, and $57.9 \%$ in the OB group (Table 4). In the OW group, boys had a significantly higher prevalence of upper stratum $\mathrm{BChE}$ levels $(38.2 \%$ vs $23.6 \%$ in girls; $P<0.001)$. However, there were no significant gender differences in the OB groups. The mean values of most anthropometric parameters, such as BMI, BMI z-score, waist and hip circumference, WHR, WHtR, some of transaminase categories, and several traditional lipid 
Table 2 Associations of hepatic panels and lipid biomarkers with adolescents weight status according to gender using linear regression analysis

\begin{tabular}{|c|c|c|c|c|c|c|}
\hline & \multicolumn{2}{|l|}{ Total } & \multicolumn{2}{|l|}{ Boys } & \multicolumn{2}{|l|}{ Girls } \\
\hline & Coefficients & $P$-value & Coefficients & $P$-value & Coefficients & $P$-value \\
\hline BPS & 0.122 & 0.000 & 0.101 & 0.000 & 0.120 & 0.000 \\
\hline BPD & -0.039 & 0.025 & -0.059 & 0.156 & -0.079 & 0.080 \\
\hline Pulse & -0.039 & 0.196 & -0.058 & 0.137 & -0.073 & 0.072 \\
\hline TP $(g / L)$ & -0.084 & 0.004 & 0.003 & 0.954 & -0.265 & 0.000 \\
\hline albumin, Alb (g/L) & -0.131 & 0.000 & -0.327 & 0.000 & -0.061 & 0.048 \\
\hline ALT (U/L) & 0.054 & 0.000 & 0.059 & 0.000 & 0.059 & 0.005 \\
\hline AST (U/L) & -0.025 & 0.000 & -0.007 & 0.886 & 0.059 & 0.000 \\
\hline ALP (U/L) & 0.053 & 0.000 & -0.020 & 0.000 & -0.028 & 0.000 \\
\hline GGT (U/L) & 0.047 & 0.011 & 0.064 & 0.006 & 0.045 & 0.417 \\
\hline BChE (U/L) & 0.111 & 0.000 & 0.101 & 0.000 & 0.054 & 0.006 \\
\hline PAI (g/L) & -0.041 & 0.155 & -0.031 & 0.430 & -0.018 & 0.641 \\
\hline BilT (mmol/L) & -0.018 & 0.551 & 0.021 & 0.582 & 0.018 & 0.656 \\
\hline $\mathrm{CB}(\mathrm{mmol} / \mathrm{L})$ & -0.007 & 0.811 & 0.036 & 0.346 & 0.033 & 0.413 \\
\hline UCB (mmol/L) & -0.029 & 0.312 & -0.001 & 0.983 & 0.008 & 0.850 \\
\hline TBA (mmol/L) & -0.048 & 0.075 & -0.038 & 0.302 & -0.073 & 0.064 \\
\hline FPG (mmol/L) & 0.005 & 0.870 & 0.030 & 0.421 & -0.006 & 0.882 \\
\hline TG (mmol/L) & 0.188 & $<0.001$ & 0.168 & $<0.001$ & 0.213 & $<0.001$ \\
\hline $\mathrm{TC}(\mathrm{mmol} / \mathrm{L})$ & 0.151 & $<0.001$ & 0.138 & 0.003 & 0.124 & 0.006 \\
\hline HDL-C (mmol/L) & -0.142 & $<0.001$ & -0.067 & 0.149 & -0.268 & $<0.001$ \\
\hline LDL-C (mmol/L) & 0.201 & $<0.001$ & 0.188 & $<0.001$ & 0.192 & $<0.001$ \\
\hline ApoAI (g/L) & -0.032 & 0.340 & -0.036 & 0.237 & -0.162 & $<0.001$ \\
\hline ApoB (g/L) & 0.255 & $<0.001$ & 0.250 & $<0.001$ & 0.232 & $<0.001$ \\
\hline
\end{tabular}

Note: $* P=K$ ruskal $-W$ allis multiple-comparison $Z$ value test. $P$-values $<0.05$ were considered statistically significant: $A=U W$ vs $N W, B=U W$ vs $O W, C=U W$ vs $O B, D=N W$ vs $\mathrm{OW}, \mathrm{E}=\mathrm{NW}$ vs $\mathrm{OB}, \mathrm{F}=\mathrm{OW}$ vs $\mathrm{OB}$.

Abbreviations: UW, underweight group; NW, normal weight group; OW, overweight group; OB, obese group; BMI, body mass index; WHR, waist-to-hip ratio; WHtR, waist-to-height ratio; BPS, systolic blood pressure; BPD, diastolic blood pressure; TP, total protein; ALT, alanine aminotransferase; AST, aspartate aminotransferase; ALP, alkaline phosphatase; GGT, gamma-glutamyl transpeptidas; PAI, pre-albumin; BilT, total bilirubin; CB, conjugated bilirubin; UCB, un-conjugated bilirubin; TBA, total bile acid; FPG, fasting plasma glucose; TG, triglycerides; TC, total cholesterol; HDL-C, high-density lipoprotein-cholesterol; LDL-C, low-density lipoprotein-cholesterol; ApoAI, apolipoprotein AI; AopB, apolipoprotein B.

biomarkers were significantly higher in the upper stratum of the BChE levels than in the lower stratum (Table $\mathrm{S} 2)$. Moreover, a multiple logistic regression analysis revealed that the plasma $\mathrm{TG}, \mathrm{TC}, \mathrm{LDL}-\mathrm{C}$, and $\mathrm{ApoB}$ levels were positively associated with the upper stratum of BChE levels when compared with the lower stratum $(\mathrm{OR}=3.76, \quad 2.19, \quad 2.84, \quad 69.07$, respectively, all $P$-values $<0.001$ ), and this was true in both the boys and girls cohorts. Furthermore, plasma ApoA1 and HDL-C levels showed negative associations with the upper stratum of the $\mathrm{BChE}$ levels when compared with the lower stratum (Table 5).

\section{The stratum of $\mathrm{BChE}$ and prevalence of MetS}

The prevalence of MetS and its components is shown in Table 6. MetS was defined according to the IDF definition, and its overall prevalence was $6.1 \%$ in boys and $5.3 \%$ in girls. Regarding the components of MetS, elevated BP was more common in boys and low HDL-C levels were more common in girls.

MetS and most of its components were more prevalent among the upper stratum than the lower stratum $\mathrm{BChE}$ levels. When adjusted age variable, Figure 2 explores the mean individual $\mathrm{BChE}$ levels based on the number of MetS components. The mean age-adjusted BChE level increased with the presence of MetS in both boys and girls ( $P$-value for trend $<0.001)$.

ROC curves for plasma BChE concentrations in subjects with MetS are shown in Figure 3. After adjusting for age, the AUC was 0.80 (95\%CI: $0.70-0.90, P<0.001)$ in girls and 0.89 (95\%CI: $0.82-0.95, P<0.001)$ in boys.

When compared with adolescents in the lower stratum of $\mathrm{BChE}$ concentration, that in the upper stratum of $\mathrm{BChE}$ levels were at a dramatically higher risk of suffering from 


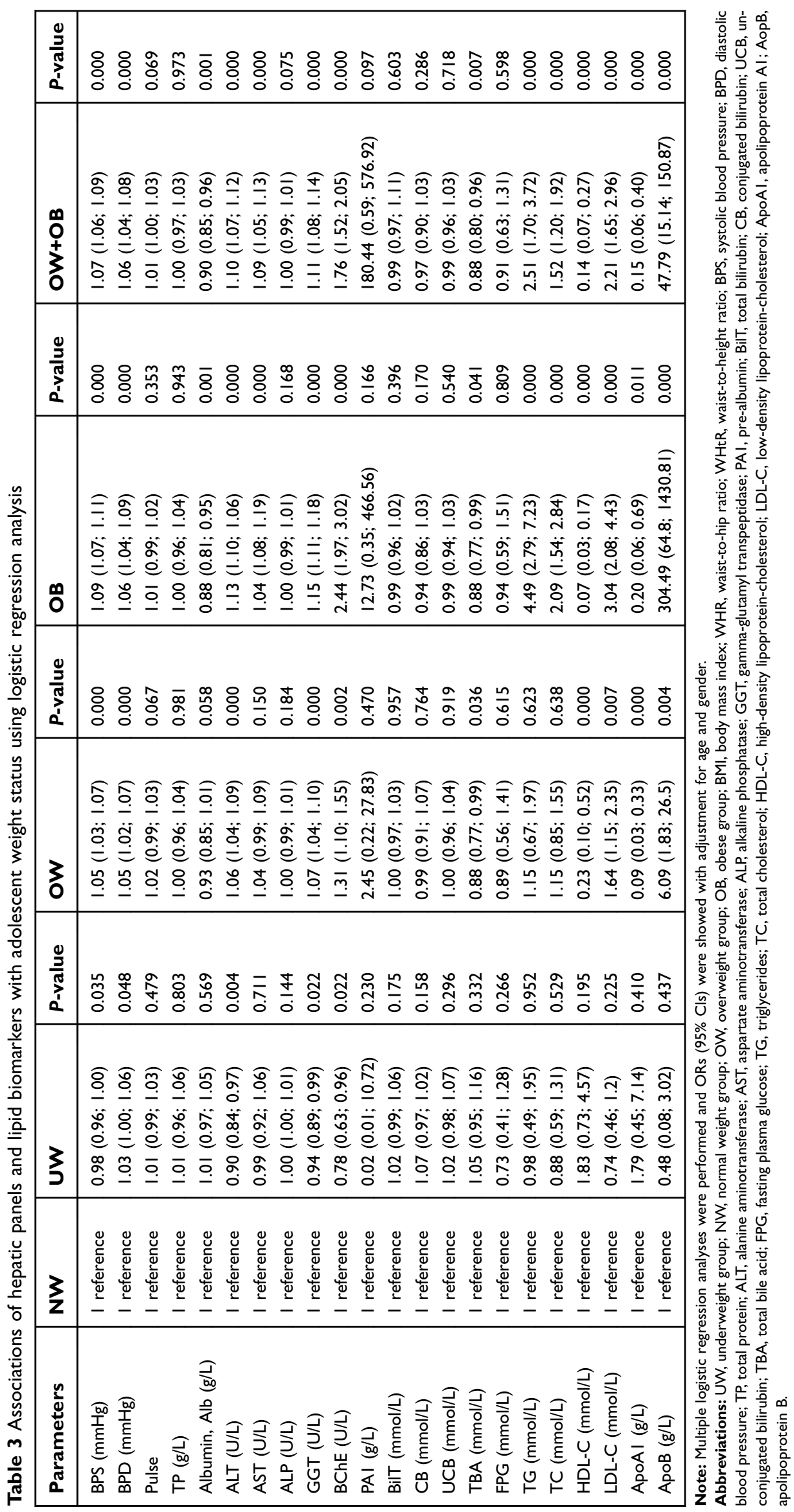


Table 4 The low or upper level of plasma BChE in the study population according to weight categories and gender

\begin{tabular}{|c|c|c|c|c|c|}
\hline Weight status & Gender & BChE low & BChE upper & n (\%) & Chi-square test \\
\hline \multicolumn{6}{|l|}{ UW } \\
\hline & $\begin{array}{l}\text { Boys } \\
\text { Girls } \\
\text { Total }\end{array}$ & $\begin{array}{l}54(86.5 \%) \\
47(77.8 \%) \\
100(82.2 \%)\end{array}$ & $\begin{array}{l}8(13.5 \%) \\
13(22.2 \%) \\
22(17.8 \%)\end{array}$ & $\begin{array}{l}62(100 \%) \\
60(100 \%) \\
122(100 \%)\end{array}$ & Chi-square test: $1.086 ; P=0.149$ \\
\hline \multicolumn{6}{|l|}{ NW } \\
\hline & $\begin{array}{l}\text { Boys } \\
\text { Girls } \\
\text { Total }\end{array}$ & $\begin{array}{l}309(87.4 \%) \\
306(80.7 \%) \\
615(84.0 \%)\end{array}$ & $\begin{array}{l}44(12.6 \%) \\
73(19.3 \%) \\
117(16.0 \%)\end{array}$ & $\begin{array}{l}353(100 \%) \\
379(100 \%) \\
732(100 \%)\end{array}$ & Chi-square test: $5.791 ; P=0.008$ \\
\hline \multicolumn{6}{|l|}{ OW } \\
\hline & $\begin{array}{l}\text { Boys } \\
\text { Girls } \\
\text { Total }\end{array}$ & $\begin{array}{l}60(61.8 \%) \\
69(76.4 \%) \\
129(68.9 \%)\end{array}$ & $\begin{array}{l}37(38.2 \%) \\
22(23.6 \%) \\
59(31.1 \%)\end{array}$ & $\begin{array}{l}97(100 \%) \\
91(100 \%) \\
188(100 \%)\end{array}$ & Chi-square test: $3.630 ; P=0.028$ \\
\hline \multicolumn{6}{|l|}{ OB } \\
\hline & $\begin{array}{l}\text { Boys } \\
\text { Girls } \\
\text { Total }\end{array}$ & $\begin{array}{l}43(39.1 \%) \\
39(46.0 \%) \\
82(42.1 \%)\end{array}$ & $\begin{array}{l}66(60.9 \%) \\
46(54.0 \%) \\
112(57.9 \%)\end{array}$ & $\begin{array}{l}109(100 \%) \\
85(100 \%) \\
194(100 \%)\end{array}$ & Chi-square test: $0.568 ; P=0.226$ \\
\hline \multicolumn{6}{|l|}{$O W+O B$} \\
\hline & $\begin{array}{l}\text { Boys } \\
\text { Girls } \\
\text { Total }\end{array}$ & $\begin{array}{l}103(49.8 \%) \\
108(61.7 \%) \\
211(55.3 \%)\end{array}$ & $\begin{array}{l}103(50.2 \%) \\
68(38.3 \%) \\
17 \mid(44.7 \%)\end{array}$ & $\begin{array}{l}206(100 \%) \\
176(100 \%) \\
382(100 \%)\end{array}$ & Chi-square test: $4.508 ; P=0.017$ \\
\hline
\end{tabular}

Abbreviations: UW, underweight group; NW, normal weight group; OW, overweight group; OB, obese group.

MetS and its components (Table 7), with the exception of boys in the high fast plasma glucose cohorts. After adjusting for age, the multivariate-adjusted OR for MetS in the upper stratum of $\mathrm{BChE}$ levels of the male cohorts was 8.73 (95\%CI: 3.49-21.84). Moreover, subjects in the upper stratum of $\mathrm{BChE}$ levels were also at a higher risk for MetS and its components, with the exception of girls who had high FPG levels and elevated BP.

\section{Discussion}

In the present study, significantly higher $\mathrm{BChE}$ concentrations were observed in $\mathrm{OB}$ adolescent subjects when compared with UW, NW, and OW adolescents, respectively. Some cross-sectional studies have shown a significant association of plasma BChE levels and BMI, dyslipidemia, and MetS in cohorts of adult subjects. ${ }^{34}$ Moreover, the mean $\mathrm{BChE}$ concentration in $\mathrm{OB}$ subjects tends to be higher than that in non-OB subjects. ${ }^{35}$ The present study investigating the correlation between plasma $\mathrm{BChE}$ levels and adolescent weight status, BMI, lipid profiles, and liver enzymes or hepatic panels were similar to those reported from previous studies conducted with adults. ${ }^{23}$ However, ours is the first large-scale study to show that plasma BChE concentrations are associated with BMI and MetS components, and were increased above their normal levels in an OB Chinese adolescent population.

\section{$\mathrm{BChE}$ and adolescent obesity}

We initially observed that $\mathrm{OB}$ adolescents have a high level of plasma $\mathrm{BChE}$ activity, whereas normal subjects have low levels of plasma $\mathrm{BChE}$ activity. Our multiple logistic regression analysis showed that the $\mathrm{BChE}$ concentration was association with being OW or OB rather than of NW. Several studies have observed associations between plasma $\mathrm{BChE}$ concentration and plasma triacylglycerol and cholesterol levels in adults. ${ }^{20,23,36}$ Furthermore, numerous studies have shown positive correlations between $\mathrm{BChE}$ concentration and the levels of lipoprotein, eg, very low-density lipoprotein, and LDL-C, and a weak negative correlation between BChE activity and HDL-C levels. ${ }^{20,36,37}$ In this study, we confirmed these results in an adolescent population, and found that triacylglycerol, cholesterol, LDL-C, and ApoB 
Table 5 Associations of parameters with the upper stratum of the BChE levels when compared with the lower stratum

\begin{tabular}{|c|c|c|c|c|c|c|c|}
\hline & \multicolumn{3}{|l|}{ ALL } & \multicolumn{2}{|l|}{ Boys } & \multicolumn{2}{|l|}{ Girls } \\
\hline & $\begin{array}{l}\text { BChE } \\
\text { lower }\end{array}$ & BChE upper & $P$-value & BChE upper & $P$-value & BChE upper & $P$-value \\
\hline Body height $(\mathrm{cm})$ & I Reference & $1.21(0.16 ; 9.04)$ & 0.851 & $7.49(0.2 ; 284.93)$ & 0.278 & $0.19(0 ; 10.43)$ & 0.417 \\
\hline Body weight (kg) & I Reference & $1.04(1.03 ; 1.05)$ & 0.000 & $1.06(1.04 ; 1.07)$ & 0.000 & $1.04(1.02 ; 1.06)$ & 0.000 \\
\hline $\begin{array}{l}\text { Waist circumference } \\
(\mathrm{cm})\end{array}$ & I Reference & $1.07(1.05 ; 1.09)$ & 0.000 & $1.09(1.07 ; 1.12)$ & 0.000 & $1.06(1.03 ; 1.08)$ & 0.000 \\
\hline Hip circumference $(\mathrm{cm})$ & I Reference & $1.09(1.07 ; 1.11)$ & 0.000 & $1.12(1.08 ; 1.15)$ & 0.000 & $1.06(1.03 ; 1.09)$ & 0.000 \\
\hline $\mathrm{BMI}\left(\mathrm{kg} \mathrm{m}^{-2}\right)$ & I Reference & $1.16(1.12 ; 1.21)$ & 0.000 & $1.20(1.14 ; 1.27)$ & 0.000 & $1.13(1.07 ; 1.19)$ & 0.000 \\
\hline BMI z-score & I Reference & $2.09(1.75 ; 2.49)$ & 0.000 & $2.43(1.88 ; 3.14)$ & 0.000 & $1.79(1.39 ; 2.30)$ & 0.000 \\
\hline Body weight z-score & I Reference & $1.93(1.62 ; 2.29)$ & 0.000 & $2.35(1.83 ; 3.02)$ & 0.000 & $1.74(1.32 ; 2.30)$ & 0.000 \\
\hline $\begin{array}{l}\text { Waist circumference } \\
\text { z-score }\end{array}$ & I Reference & $2.1(1.76 ; 2.5 I)$ & 0.000 & $2.64(2.04 ; 3.43)$ & 0.000 & I.8I (I.38; 2.37) & 0.000 \\
\hline $\begin{array}{l}\text { Hip circumference } \\
\text { z-score }\end{array}$ & I Reference & $2.1(1.75 ; 2.5 I)$ & 0.000 & $2.60(1.99 ; 3.38)$ & 0.000 & $1.68(1.30 ; 2.18)$ & 0.000 \\
\hline WHtR & I Reference & $4.51(2.48 ; 9.06)$ & 0.000 & $1.25(1.07 ; 1.54)$ & 0.000 & $8.38(2.06 ; 11.40)$ & 0.000 \\
\hline WHR & I Reference & $\begin{array}{l}16.90(10.06 \\
35.22)\end{array}$ & 0.000 & $33.68(25.12 ; 43.65)$ & 0.000 & $\begin{array}{l}49.12(37.5 \\
66.32)\end{array}$ & 0.001 \\
\hline BPS (mm Hg) & I Reference & $1.03(1.02 ; 1.05)$ & 0.000 & $1.04(1.03 ; 1.06)$ & 0.000 & $1.04(1.02 ; 1.06)$ & 0.000 \\
\hline BPD $(\mathrm{mmHg})$ & I Reference & $1.03(1.01 ; 1.05)$ & 0.001 & $1.03(1.00 ; 1.06)$ & 0.032 & $1.04(1.01 ; 1.07)$ & 0.008 \\
\hline Pulse & I Reference & $1.02(1.00 ; 1.03)$ & 0.011 & $1.01(0.99 ; 1.03)$ & 0.202 & $1.02(1.00 ; 1.04)$ & 0.017 \\
\hline $\operatorname{TP}(g / L)$ & I Reference & $1.08(1.04 ; 1.13)$ & 0.000 & $1.08(1.02 ; 1.14)$ & 0.012 & $1.09(1.03 ; 1.15)$ & 0.002 \\
\hline albumin, Alb (g/L) & I Reference & 1.01 (0.98; I.05) & 0.499 & $1.09(0.99 ; 1.20)$ & 0.066 & $1.00(0.96 ; 1.04)$ & 0.967 \\
\hline ALT (U/L) & I Reference & $1.06(1.04 ; 1.07)$ & 0.000 & $1.06(1.04 ; 1.08)$ & 0.000 & $1.06(1.03 ; 1.10)$ & 0.000 \\
\hline AST (U/L) & I Reference & $1.02(0.99 ; 1.03)$ & 0.079 & $1.10(1.05 ; 1.16)$ & 0.000 & $1.00(0.99 ; 1.02)$ & 0.778 \\
\hline ALP (U/L) & I Reference & $1.00(0.99 ; । ; 01)$ & 0.773 & $1.00(0.99 ; 1.00)$ & 0.469 & $1.00(0.99 ; 1.01)$ & 0.565 \\
\hline GGT (U/L) & I Reference & $1.07(1.05 ; 1.09)$ & 0.000 & $1.09(1.06 ; 1.12)$ & 0.000 & $1.07(1.04 ; 1.11)$ & 0.000 \\
\hline PAI (g/L) & I Reference & $\begin{array}{l}32.39(0.85 \\
1236.03)\end{array}$ & 0.061 & $28.19(3.54 ; 254.37)$ & 0.000 & $2.25(0.18 ; 28.22)$ & 0.531 \\
\hline BilT (mmol/L) & I Reference & $0.98(0.95 ; 1.01)$ & 0.106 & $0.98(0.95 ; 1.01)$ & 0.214 & $0.97(0.92 ; 1.02)$ & 0.196 \\
\hline $\mathrm{CB}(\mathrm{mmol} / \mathrm{L})$ & I Reference & $0.91(0.84 ; 0.97)$ & 0.007 & $0.88(0.79 ; 0.98)$ & 0.014 & $0.89(0.77 ; 1.02)$ & 0.082 \\
\hline UCB (mmol/L) & I Reference & $0.98(0.95 ; 1.02)$ & 0.309 & $0.98(0.94 ; 1.03)$ & 0.486 & $0.97(0.90 ; 1.04)$ & 0.350 \\
\hline TBA (mmol/L) & I Reference & $0.99(0.91 ; 1.07)$ & 0.757 & $1.05(0.95 ; 1.16)$ & 0.372 & $0.90(0.78 ; 1.04)$ & 0.140 \\
\hline FPG (mmol/L) & I Reference & $1.35(0.92 ; 1.99)$ & 0.126 & $1.14(0.65 ; 2.02)$ & 0.645 & I.6I (0.93; 2.79$)$ & 0.091 \\
\hline $\mathrm{TG}(\mathrm{mmol} / \mathrm{L})$ & I Reference & $3.76(2.50 ; 5.68)$ & 0.000 & $4.28(2.42 ; 7.56)$ & 0.000 & $3.30(1.82 ; 5.99)$ & 0.000 \\
\hline $\mathrm{TC}(\mathrm{mmol} / \mathrm{L})$ & I Reference & $2.19(1.70 ; 2.82)$ & 0.000 & $2.65(1.82 ; 3.86)$ & 0.000 & I.9I (I.35; 2.7I) & 0.000 \\
\hline HDL-C (mmol/L) & I Reference & $0.18(0.09 ; 0.35)$ & 0.000 & $0.12(0.04 ; 0.33)$ & 0.000 & $0.21(0.08 ; 0.55)$ & 0.001 \\
\hline LDL-C (mmol/L) & I Reference & $2.84(2.09 ; 3.86)$ & 0.000 & $3.72(2.35 ; 5.89)$ & 0.000 & $2.27(1.50 ; 3.43)$ & 0.000 \\
\hline ApoAI (g/L) & I Reference & $0.32(0.12 ; 0.83)$ & 0.019 & $0.36(0.09 ; 1.49)$ & 0.160 & $0.26(0.07 ; 1.00)$ & 0.050 \\
\hline ApoB $(g / L)$ & I Reference & $\begin{array}{l}69.07(21.78 \\
219.04)\end{array}$ & 0.000 & $\begin{array}{l}\text { II0.4I (20.49; } \\
594.89)\end{array}$ & 0.000 & $\begin{array}{l}47.04(9.47 ; \\
233.7 \mathrm{I})\end{array}$ & 0.000 \\
\hline
\end{tabular}

Note: multiple logistic regression analyses were performed and ORs ( $95 \% \mathrm{Cls})$ were showed with adjustment for age and gender.

Abbreviations: UW, underweight group; NW, normal weight group; OW, overweight group; OB, obese group; BMI, body mass index; WHR, waist-to-hip ratio; WHtR, waist-to-height ratio; BPS, systolic blood pressure; BPD, diastolic blood pressure; TP, total protein; ALT, alanine aminotransferase; AST, aspartate aminotransferase; ALP, alkaline phosphatase; GGT, gamma-glutamyl transpeptidas; PAI, pre-albumin; BilT, total bilirubin; CB, conjugated bilirubin; UCB, un-conjugated bilirubin; TBA, total bile acid; FPG, fasting plasma glucose; TG, triglycerides; TC, total cholesterol; HDL-C, high-density lipoprotein-cholesterol; LDL-C, low-density lipoprotein-cholesterol; ApoAI, apolipoprotein AI; AopB, apolipoprotein B.

levels were positively associated with the upper stratum of BChE levels compared with the lower stratum. Lipoproteins have a phosphorylcholine group that can interact with $\mathrm{BChE}$, and this suggests that they may play a role in lipoprotein metabolism. ${ }^{38}$ Furthermore, other studies have shown that
BChE plays a role in lipid metabolism, either directly or via a synergistic action with cholesterol esterase. ${ }^{39,40}$

Several animal studies have shown a statistically significant increase in plasma ChE levels during fattening in pigs (the same breed), which might be due to an adaptative 
Table 6 Prevalence of metabolic syndrome and its components

\begin{tabular}{|c|c|c|c|c|c|c|c|c|c|}
\hline & \multirow[t]{2}{*}{ Boys } & \multirow[t]{2}{*}{ Girls } & \multirow[t]{2}{*}{$P$-value } & \multicolumn{3}{|l|}{ Boys } & \multicolumn{3}{|l|}{ Girls } \\
\hline & & & & $\begin{array}{l}\text { BChE } \\
\text { low }\end{array}$ & $\begin{array}{l}\text { BChE } \\
\text { upper }\end{array}$ & $P$-value & $\begin{array}{l}\text { BChE } \\
\text { low }\end{array}$ & $\begin{array}{l}\text { BChE } \\
\text { upper }\end{array}$ & $P$-value \\
\hline $\mathrm{MtS}$ & $6.1(0.9)$ & $5.3(0.9)$ & 0.328 & $0.4(0.3)$ & I5.4 (2.8) & $<0.001$ & $2.2(0.6)$ & | $4.3(2.8)$ & $<0.001$ \\
\hline Abdominal obesity (\%) & $25.1(1.7)$ & $23.8(1.7)$ & 0.309 & $13.9(1.6)$ & $57.3(4.0)$ & $<0.001$ & $18.3(3.6)$ & $38.5(3.9)$ & $<0.001$ \\
\hline Elevated BP (\%) & $30.9(1.8)$ & $9.2(1.1)$ & $<0.001$ & $24.1(2.0)$ & $53.4(4.0)$ & $<0.001$ & $4.8(1.0)$ & $22.5(3.3)$ & $<0.001$ \\
\hline High FPG (\%) & I.6 (0.5) & $1.9(0.6)$ & 0.491 & I.5 (0.6) & I.I (0.8) & 0.643 & I.I (0.5) & $4.4(1.6)$ & 0.069 \\
\hline High TG (\%) & $5.3(0.9)$ & $3.8(0.8)$ & 0.116 & $2.2(0.7)$ & $15.7(3.0)$ & $<0.0001$ & $2.2(0.7)$ & $8.8(2.3)$ & 0.009 \\
\hline Low HDL-C (\%) & $18.9(1.6)$ & $38.8(2.0)$ & $<0.001$ & $15.3(1.7)$ & $30.3(3.7)$ & 0.002 & $35.5(2.2)$ & $50.5(4.0)$ & 0.008 \\
\hline
\end{tabular}

Note: Data are presented as percentage (standard error). $P$-values were obtained by using weighted Chi-square test.

Abbreviations: UW, underweight group; NW, normal weight group; OW, overweight group; OB, obese group; BMI, body mass index; WHR, waist-to-hip ratio; WHtR, waist-to-height ratio; BPS, systolic blood pressure; BPD, diastolic blood pressure; TP, total protein; ALT, alanine aminotransferase; AST, aspartate aminotransferase; ALP, alkaline phosphatase; GGT, gamma-glutamyl transpeptidase; PAI, pre-albumin; BilT, total bilirubin; CB, conjugated bilirubin; UCB, un-conjugated bilirubin; TBA, total bile acid; FPG, fasting plasma glucose; TG, triglycerides; TC, total cholesterol; HDL-C, high-density lipoprotein-cholesterol; LDL-C, low-density lipoprotein-cholesterol; ApoAI, apolipoprotein AI; AopB, apolipoprotein B.

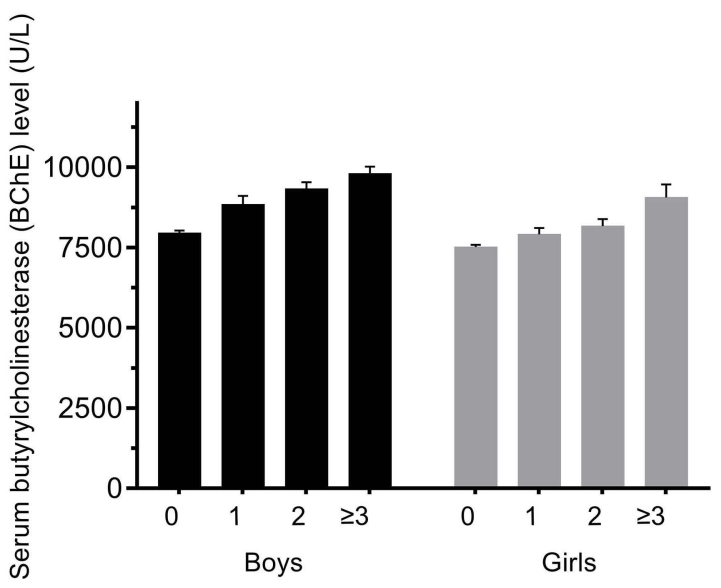

No. of metabolic syndrome components

Figure 2 Age-adjusted mean plasma BChE levels by the number of components of metabolic syndrome (error bars represent standard error of the mean). Black columns represent data for boys, and shaded columns represent data for girls.

increase of the hepatic synthesis of $\mathrm{BChE}$ in response to the increased lipid metabolism. ${ }^{41}$ Another study in mice revealed an increase in the plasma $\mathrm{ChE}$ levels of lean mice on a high carbohydrate diet, which suggested a marked reduction $(40 \%)$ in $\mathrm{BChE}$ activity occurred in the liver of genetically diabetic mice when starved for $24 \mathrm{hrs} .{ }^{42}$ These findings reveal that an increase in plasma ChE levels is a result of obesity or weight gain, rather than a cause.

\section{BChE and MetS in adolescents}

The functional significance of elevated plasma BChE level in individuals with risk factors for metabolism syndrome is also unclear. Several mechanisms could explain this association. Previous study suggested that plasma BChE levels were correlated with waist circumference and components of visceral fatarea. ${ }^{43}$ Our present study in adolescents found an association between BChE levels and waist circumference, waist-to-hip ratio, and waist-to-height ratio. Increased visceral fat has been confirmed to be associated with future insulin resistance, ${ }^{44}$ and this association may partially be as a result of insulin resistance resulting from plasma BChE and visceral adiposity. Simultaneously, an increase in the $\mathrm{BChE}$ level could indicate an increase in fat infiltration in the liver, and a higher BChE level has been frequently observed in non-alcoholic fatty liver disease. ${ }^{45}$ Non-alcoholic fatty liver disease is increasingly being regarded as a manifestation of MetS and insulin resistance. Another mechanism for these associations may be inflammation. BChE catalyzes the hydrolysis of acetylcholine, succinylcholine, and butyrylcholine. ${ }^{18}$ As widely reported, the acetylcholine plays an anti-inflammatory activity role physiological status. ${ }^{18}$ Elevated plasma BChE levels could lead to reduced acetylcholine levels and low-grade inflammation, ${ }^{46}$ which may partially be involved in the pathogenesis of MetS associated with plasma BChE, because inflammation is likely to induce insulin resistance. $^{47}$ Thirdly, a mechanism for these associations may be polymorphisms. The polymorphisms of $\mathrm{BuChE}$ have been reported to be associated with BMI, obesity, and hypertriglyceridemia in adolescents. A southern Brazil study has suggested that individuals with innately high BChE activity tend to be thinner, and that people who gain weight have increased levels of BChE synthesis. They suggested that $1914 \mathrm{G}$ allele showed a significantly higher frequency in the OB group. Furthermore, when compared with 1914A carriers, the carriers of $1914 \mathrm{G}$ 

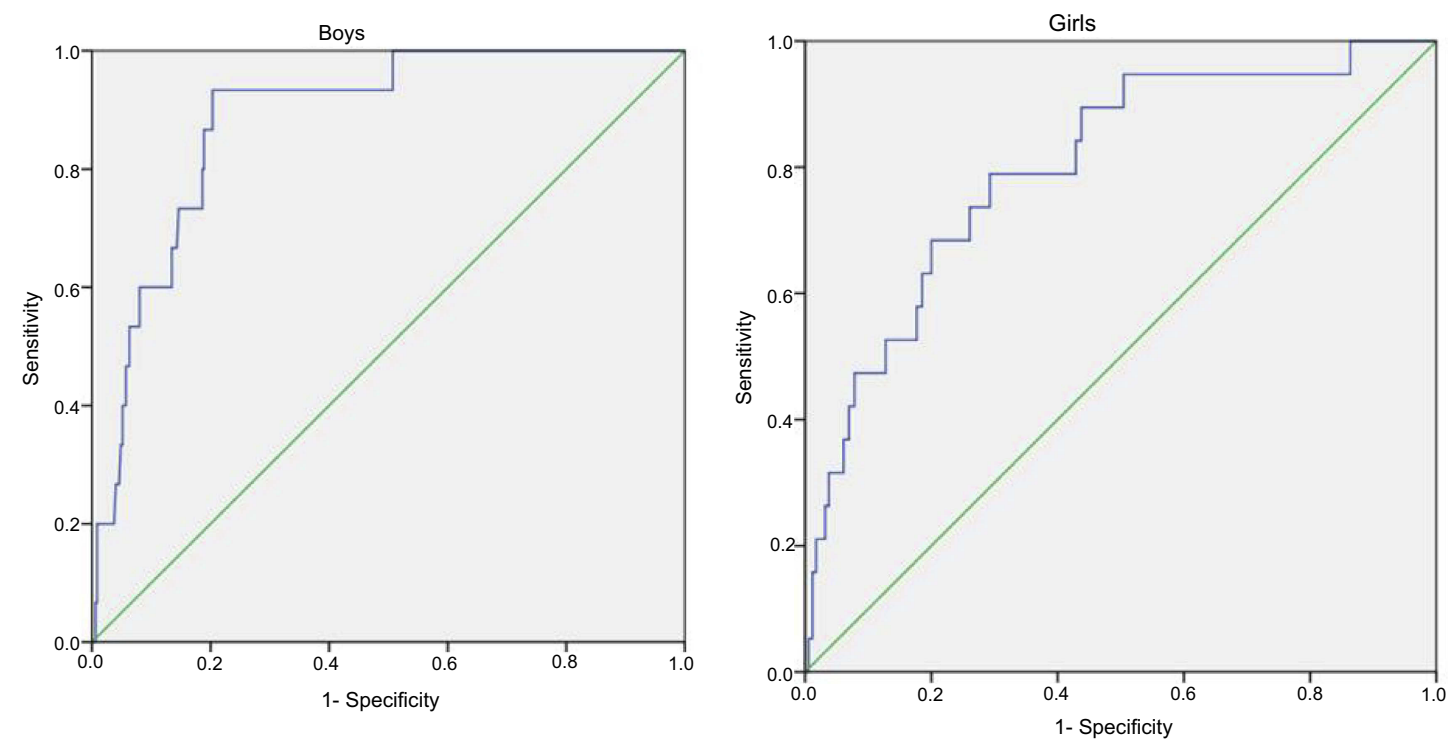

Figure 3 Receiver operating characteristic curves of plasma BChE level for metabolic syndrome in girls and boys.

Table 7 Multivariate-adjusted odds ratios and $95 \%$ confidence intervals for metabolic syndrome and its components according to BChE level in boys and girls Chinese adolescent

\begin{tabular}{|c|c|c|c|c|c|c|}
\hline & \multicolumn{3}{|l|}{ Boys } & \multicolumn{3}{|l|}{ Girls } \\
\hline & BChE low & BChE upper & $P$-value & BChE low & BChE upper & $P$-value \\
\hline MtS & I Reference & $8.73(3.49-21.84)$ & $<0.001$ & I Reference & $1.71(1.35-21.70)$ & $<0.001$ \\
\hline Abdominal obesity (\%) & I Reference & $8.89(4.61-13.50)$ & $<0.001$ & I Reference & $1.67(1.29-2.16)$ & $<0.001$ \\
\hline Elevated BP (\%) & I Reference & $3.32(2.02-5.45)$ & $<0.001$ & I Reference & $2.08(0.99-4.38)$ & 0.053 \\
\hline High TG (\%) & I Reference & $8.09(3.01-21.76)$ & $<0.001$ & I Reference & $4.29(1.45-12.72)$ & 0.009 \\
\hline High FPG (\%) & I Reference & $0.747(0.08-6.77)$ & 0.796 & I Reference & $4.14(0.91-18.85)$ & 0.066 \\
\hline Low HDL-C (\%) & I Reference & $2.32(1.33-4.05)$ & 0.003 & I Reference & $1.86(1.15-2.99)$ & 0.012 \\
\hline
\end{tabular}

BChE gene allele display lower mean BChE activity. Simultaneously, higher mean BMI and TG levels were found in the $1914 \mathrm{G}$ carriers when compared with the 1914A homozygotes. ${ }^{48}$ Therefore, it is possible that 1914G BChE gene allele can be interfering in lipolysis, hyperglycemia, gluconeogenesis, and body fat distribution. This lower activity may cause an imbalance in lipid metabolism, which could lead to a lower ability to maintain metabolic homeostasis. The previous study ${ }^{49}$ revealed that plasma BChE plays a role in the cleavage of ghrelin. Ghrelin, the "hunger hormone", is a peptide hormone produced by the stomach and involved in regulating the distribution, rate of use of energy, induction of adiposity, the stimulation of growth hormone release, and weight gain. Desacyl ghrelin is produced as a result of ghrelin cleavage, and it plays a role of cell proliferation and stimulates adipogenesis. This function indicates an important role for butylcholinesterase (BChE) in the development and progression of both obesity and MetS. ${ }^{49}$

Above all, the association between plasma $\mathrm{BChE}$ activity and TC, LDL-cholesterol, and TGs strongly suggests its value as a risk marker for obesity and MetS in adolescents. As BChE activity is easily measured for a low cost, its predictive value when used with other markers for assessing MetS risk should not be overlooked. ${ }^{34}$

Our present study has several limitations that should be mentioned. First, due to the cross-sectional nature of the study, temporal relations between $\mathrm{BChE}$ and the outcomes of adolescent obesity cannot be discerned, and it remains unclear whether a higher $\mathrm{BChE}$ level is a direct risk factor for adolescent obesity and metabolism syndrome or simply an epiphenomenon. Therefore, it is necessary to perform a prospective study to confirm the causal relationship between plasma $\mathrm{BChE}$ levels and obesity and MetS among adolescents. Secondly, 
enrolled adolescent students belonged to a single ethnic cohort and they were registered in the same city. Even though they may apply to other east Asian adolescents, our conclusion may not be representative of the general adolescents population. Thirdly, we could not ignore the role that the physiological effect of puberty on insulin resistance. Some researchers have shown that adolescents population suffer from transient insulin resistance during puberty. ${ }^{50}$ Finally, detailed information about polymorphisms of BChE was not available. Polymorphisms of $\mathrm{BChE}$ have been reported to be associated with obesity in adolescents. However, the corresponding data on the pubertal stage of our research participants were not included in this HMPSPM dataset. Here, the pubertal stage of the enrolled adolescents was not directly considered in our study. Even though, we performed analysis by involved age and gender as a confounding variable in the multiple logistic regression analysis to minimize the influence of this limitation. Even with these potential limitations, our study results are of good general applicability because nationally representative cohorts of children and adolescents from China were used in the study. In addition, the reliability of our findings is strengthened by a large number of normal-weight participants.

\section{Conclusion}

In the present study, we investigated plasma $\mathrm{BChE}$ as a hepatic metabolism biomarker that can predict $\mathrm{OW}$, obesity, and MetS in Chinese adolescents. Our results showed: (1) a positive association between upper strata plasma BChE levels with adolescents $\mathrm{OW}$ and an even greater association with obesity. (2) In the OW cohort, boys had a significantly higher prevalence of upper stratum BChE levels, but there were no significant genderrelated differences in the $\mathrm{OB}$ cohorts. (3) Plasma TG, TC, LDL-C, and ApoB levels were positively associated with the upper stratum of $\mathrm{BChE}$ levels when compared with the lower stratum, and this was true for both boys and girls. (4) Plasma BChE levels were positively associated with MetS and its components. These findings contribute to our understanding of the association of plasma BChE concentration and MetS or its components in Chinese adolescent's cohorts. Larger prospective studies are needed to confirm our results.

\section{Acknowledgment}

This work was supported by the China Postdoctoral Science Foundation (grant: 2018M640270), and National Science Foundation of China (grant: 71774173 and grant: 81600370).

\section{Disclosure}

The authors report no conflicts of interest in this work.

\section{References}

1. Pelone F, Specchia ML, Veneziano MA, et al. Economic impact of childhood obesity on health systems: a systematic review. Obes Rev. 2012;13(5):431-440. doi:10.1111/j.1467-789X.2011.00968.x

2. Wang Y, Beydoun MA, Liang L, Caballero B, Kumanyika SK. Will all Americans become overweight or obese? Estimating the progression and cost of the US obesity epidemic. Obesity (Silver Spring). 2008;16(10):2323-2330. doi:10.1038/oby.2008.351

3. Nasreddine L, Naja F, Akl C, et al. Dietary, lifestyle and socio-economic correlates of overweight, obesity and central adiposity in Lebanese children and adolescents. Nutrients. 2014;6 (3):1038-1062. doi:10.3390/nu6031038

4. Koren D, Chirinos JA, Katz LE, et al. Interrelationships between obesity, obstructive sleep apnea syndrome and cardiovascular risk in obese adolescents. Int J Obes (Lond). 2015;39(7):1086-1093. doi:10.1038/ijo.2015.67

5. Nicholas LM, Morrison JL, Rattanatray L, Zhang S, Ozanne SE, McMillen IC. The early origins of obesity and insulin resistance: timing, programming and mechanisms. Int J Obes (Lond). 2016;40 (2):229-238. doi:10.1038/ijo.2015.178

6. Wells JC, Cole TJ. Height, adiposity and hormonal cardiovascular risk markers in childhood: how to partition the associations? Int $J$ Obes (Lond). 2014;38(7):930-935. doi:10.1038/ ijo. 2014.24

7. Jones-Smith JC, Gordon-Larsen P, Siddiqi A, Popkin BM. Is the burden of overweight shifting to the poor across the globe? Time trends among women in 39 low- and middle-income countries (1991-2008). Int $J$ Obes (Lond). 2012;36(8):1114-1120. doi:10.1038/ijo.2011.179

8. Collaboration NCDRF. Worldwide trends in body-mass index, underweight, overweight, and obesity from 1975 to 2016: a pooled analysis of 2416 population-based measurement studies in 128.9 million children, adolescents, and adults. Lancet. 2017;390(10113):2627-2642. doi:10.1016/S0140-6736(17)32129-3

9. Lau DC, Dhillon B, Yan H, Szmitko PE, Verma S. Adipokines: molecular links between obesity and atheroslcerosis. Am J Physiol Heart Circ Physiol. 2005;288(5):H2031-H2041. doi:10.1152/ ajpheart.01058.2004

10. Ng M, Fleming T, Robinson M, et al. Global, regional, and national prevalence of overweight and obesity in children and adults during 1980-2013: a systematic analysis for the Global Burden of Disease Study 2013. Lancet. 2014;384(9945):766-781. doi:10.1016/S01406736(14)60460-8

11. Friend A, Craig L, Turner S. The prevalence of metabolic syndrome in children: a systematic review of the literature. Metab Syndr Relat Disord. 2013;11(2):71-80. doi:10.1089/met.2012.0122

12. Massoulie J, Pezzementi L, Bon S, Krejci E, Vallette FM. Molecular and cellular biology of cholinesterases. Prog Neurobiol. 1993;41 (1):31-91.

13. Malinger G, Zakut H, Soreq H. Cholinoceptive properties of human primordial, preantral, and antral oocytes: in situ hybridization and biochemical evidence for expression of cholinesterase genes. $J \mathrm{Mol}$ Neurosci. 1989;1(2):77-84.

14. Dubovy P, Haninec P. Non-specific cholinesterase activity of the developing peripheral nerves and its possible function in cells in intimate contact with growing axons of chick embryo. Int $J$ Dev Neurosci. 1990;8(5):589-602.

15. Vellom DC, Radic Z, Li Y, Pickering NA, Camp S, Taylor P. Amino acid residues controlling acetylcholinesterase and butyrylcholinesterase specificity. Biochemistry. 1993;32(1):12-17. 
16. Harel M, Sussman JL, Krejci E, et al. Conversion of acetylcholinesterase to butyrylcholinesterase: modeling and mutagenesis. Proc Natl Acad Sci US A. 1992;89(22):10827-10831. doi:10.1073/pnas.89.22.10827

17. Alcantara VM, Oliveira LC, Rea RR, Suplicy HL, Chautard-FreireMaia EA. Butyrylcholinesterase activity and metabolic syndrome in obese patients. Clin Chem Lab Med. 2005;43(3):285-288. doi:10.1515/CCLM.2005.048

18. Das UN. Acetylcholinesterase and butyrylcholinesterase as possible markers of low-grade systemic inflammation. Med Sci Monit. 2007;13(12):RA214-RA221.

19. Ramachandran J, Sajith KG, Priya S, Dutta AK, Balasubramanian KA. Serum cholinesterase is an excellent biomarker of liver cirrhosis. Trop Gastroenterol. 2014;35(1):15-20.

20. Oda E. Associations between serum cholinesterase and incident hyper-LDL cholesterolemia, hypertriglyceridemia and hypo-HDL cholesterolemia as well as changes in lipid levels in a health screening population. Atherosclerosis. 2015;241(1):1-5. doi:10.1016/j. atherosclerosis.2015.04.804

21. Sato KK, Hayashi T, Maeda I, et al. Serum butyrylcholinesterase and the risk of future type 2 diabetes: the Kansai Healthcare Study. Clin Endocrinol (Oxf). 2014;80(3):362-367. doi:10.1111/cen.12171

22. Arbel Y, Shenhar-Tsarfaty S, Waiskopf N, et al. Decline in serum cholinesterase activities predicts 2-year major adverse cardiac events. Mol Med. 2014;20:38-45. doi:10.2119/molmed.2013.00139

23. Randell EW, Mathews MS, Zhang H, Seraj JS, Sun G. Relationship between serum butyrylcholinesterase and the metabolic syndrome. Clin Biochem. 2005;38(9):799-805. doi:10.1016/j.clinbiochem.2005.04.008

24. Duchnowicz P, Ziobro A, Rapacka E, Koter-Michalak M, Bukowska B. Changes in cholinesterase activity in blood of adolescent with metabolic syndrome after supplementation with extract from aronia melanocarpa. Biomed Res Int. 2018;2018:5670145. doi:10.1155/2018/5670145

25. Zhao Z, Ma Y, Han Y, et al. Psychosocial correlates of food addiction and its association with quality of life in a non-clinical adolescent sample. Nutrients. 2018;10(7):837. doi:10.3390/nu10070837

26. Physical status: the use and interpretation of anthropometry. Report of a WHO expert committee. World Health Organ Tech Rep Ser. 1995;854:1-452.

27. Bergman RN, Stefanovski D, Buchanan TA, et al. A better index of body adiposity. Obesity (Silver Spring). 2011;19(5):1083-1089. doi:10.1038/oby.2011.38

28. Wang J, Zhang L, Wang F, Liu L, Wang H; China National Survey of Chronic Kidney Disease Working Group. Prevalence, awareness, treatment, and control of hypertension in China: results from a national survey. Am J Hypertens. 2014;27(11):1355-1361. doi:10.1093/ajh/hpu053

29. Lewis PJ, Lowing RK, Gompertz D. Automated discrete kinetic method for erythrocyte acetylcholinesterase and plasma cholinesterase. Clin Chem. 1981;27(6):926-929.

30. Zhou BF; Cooperative Meta-Analysis Group of the Working Group on Obesity in C. Predictive values of body mass index and waist circumference for risk factors of certain related diseases in Chinese adults-study on optimal cut-off points of body mass index and waist circumference in Chinese adults. Biomed Environ Sci. 2002;15 (1):83-96

31. Ji CY; Working Group on Obesity in C. Report on childhood obesity in China (1)-body mass index reference for screening overweight and obesity in Chinese school-age children. Biomed Environ Sci. 2005;18 (6):390-400

32. Zimmet P, Alberti KG, Kaufman F, et al. The metabolic syndrome in children and adolescents - an IDF consensus report. Pediatr Diabetes. 2007;8(5):299-306. doi:10.1111/j.1399-5448.2007.00271.x
33. Park JM, Lee JY, Lee DC, Lee YJ. Serum gamma-glutamyltransferase level and metabolic syndrome in children and adolescents: Korean National Health and Nutrition Examination Survey. J Diabetes Investig. 2017;9:522-528.

34. Vallianou NG, Evangelopoulos AA, Bountziouka V, et al. Association of butyrylcholinesterase with cardiometabolic risk factors among apparently healthy adults. $J$ Cardiovasc Med (Hagerstown). 2014;15(5):377-383. doi:10.2459/JCM.0b013e3283 627700

35. Li B, Duysen EG, Lockridge O. The butyrylcholinesterase knockout mouse is obese on a high-fat diet. Chem Biol Interact. 2008;175 (1-3):88-91. doi:10.1016/j.cbi.2008.03.009

36. Calderon-Margalit R, Adler B, Abramson JH, Gofin J, Kark JD. Butyrylcholinesterase activity, cardiovascular risk factors, and mortality in middle-aged and elderly men and women in Jerusalem. Clin Chem. 2006;52(5):845-852. doi:10.1373/clinchem.2005.059857

37. Cucuianu M, Popescu TA, Opincaru A, Haragus S. Serum pseudocholinesterase and ceruloplasmin in various types of hyperlipoproteinemia. Clin Chim Acta. 1975;59(1):19-27.

38. Kutty KM, Payne RH. Serum pseudocholinesterase and very-lowdensity lipoprotein metabolism. J Clin Lab Anal. 1994;8(4):247-250.

39. Rustemeijer C, Schouten JA, Voerman HJ, Beynen AC, Donker AJ, Heine RJ. Is pseudocholinesterase activity related to markers of triacylglycerol synthesis in Type II diabetes mellitus? Clin Sci (Lond). 2001;101(1):29-35.

40. Abbott CA, Mackness MI, Kumar S, et al. Relationship between serum butyrylcholinesterase activity, hypertriglyceridaemia and insulin sensitivity in diabetes mellitus. Clin Sci (Lond). 1993;85 (1):77-81.

41. Popescu TA, Fekete T, Popescu E, Bojthy I, Laszlo M. Serum pseudocholinesterase activity during experimental fattening. Med Interne. 1976;14(1):71-73.

42. Kutty KM, Huang SN, Kean KT. Pseudocholinesterase in obesity: hypercaloric diet induced changes in experimental obese mice. Experientia. 1981;37(11):1141-1142.

43. Iwasaki T, Yoneda M, Nakajima A, Terauchi Y. Serum butyrylcholinesterase is strongly associated with adiposity, the serum lipid profile and insulin resistance. Intern Med. 2007;46(19):1633-1639.

44. Hayashi T, Boyko EJ, McNeely MJ, Leonetti DL, Kahn SE, Fujimoto WY. Visceral adiposity, not abdominal subcutaneous fat area, is associated with an increase in future insulin resistance in Japanese Americans. Diabetes. 2008;57(5):1269-1275. doi:10.2337/db07-1378

45. Nomura F, Ohnishi K, Koen H, et al. Serum cholinesterase in patients with fatty liver. J Clin Gastroenterol. 1986;8(5):599-602.

46. Kamal MA, Tan Y, Seale JP, Qu X. Targeting BuChE-inflammatory pathway by SK0506 to manage type 2 diabetes and Alzheimer disease. Neurochem Res. 2009;34(12):2163-2169. doi:10.1007/ s11064-009-0011-z

47. Hotamisligil GS. Inflammation and metabolic disorders. Nature. 2006;444(7121):860-867. doi:10.1038/nature05485

48. Lima JK, Leite N, Turek LV, et al. 1914G variant of BCHE gene associated with enzyme activity, obesity and triglyceride levels. Gene. 2013;532(1):24-26. doi:10.1016/j.gene.2013.08.068

49. De Vriese C, Gregoire F, Lema-Kisoka R, Waelbroeck M, Robberecht P, Delporte C. Ghrelin degradation by serum and tissue homogenates: identification of the cleavage sites. Endocrinology. 2004;145(11):4997-5005. doi:10.1210/en.2004-0569

50. Moran A, Jacobs DR Jr., Steinberger J, et al. Insulin resistance during puberty: results from clamp studies in 357 children. Diabetes. 1999;48(10):2039-2044. 


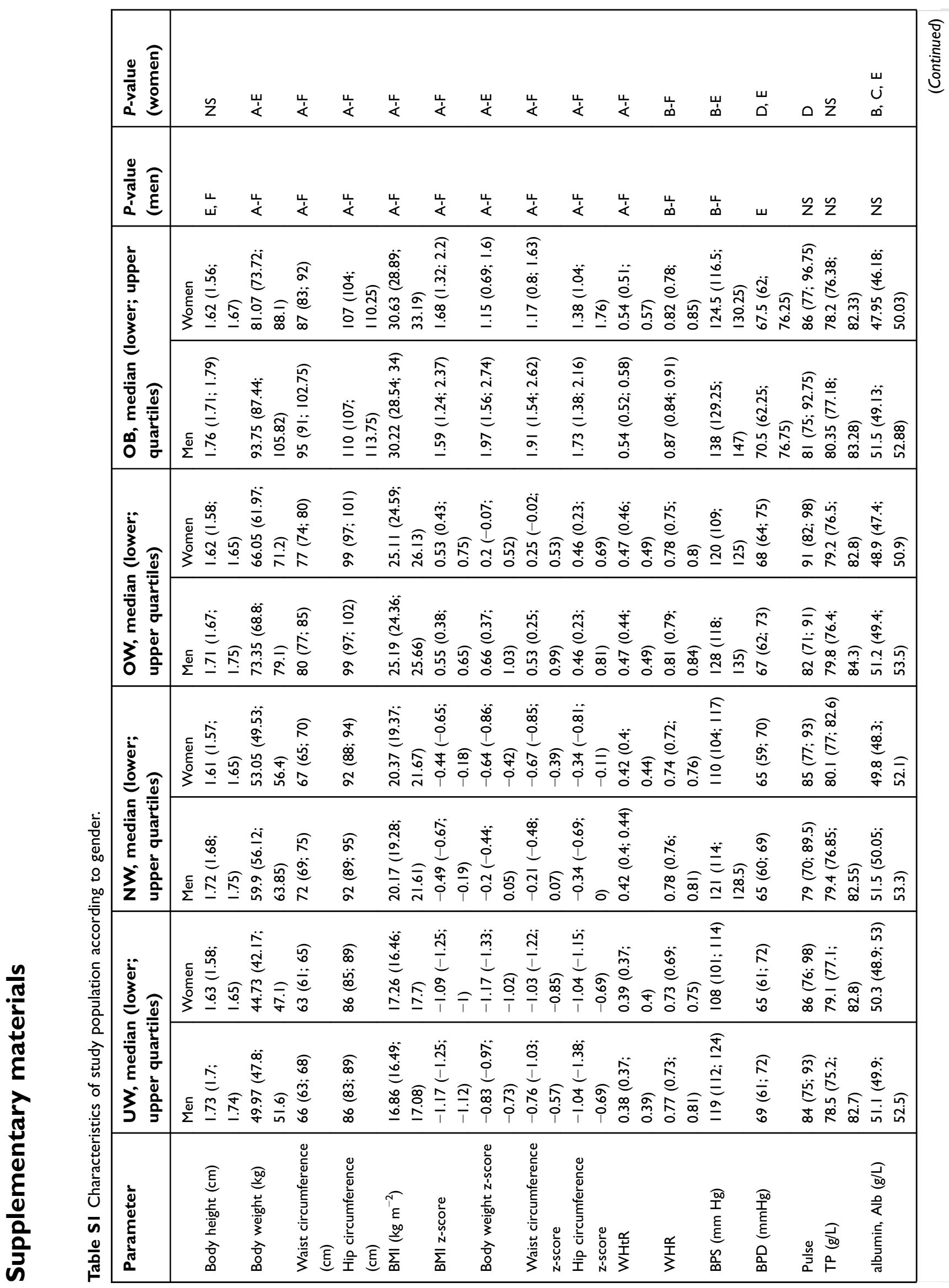




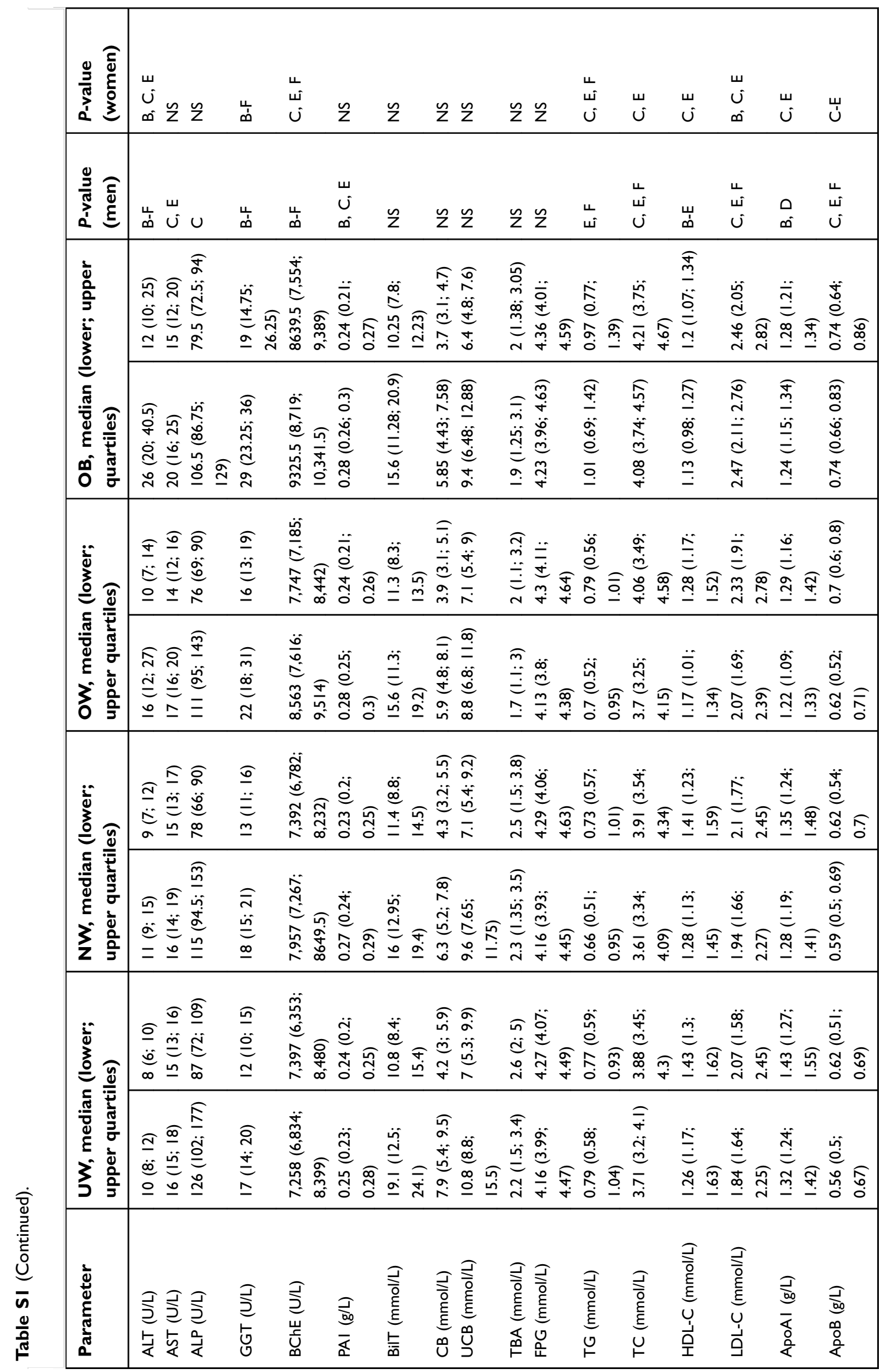




\begin{tabular}{|c|c|c|c|}
\hline 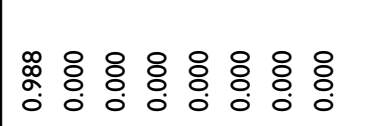 & 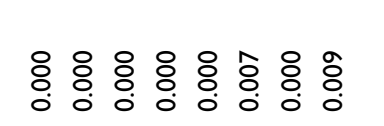 & 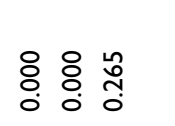 & 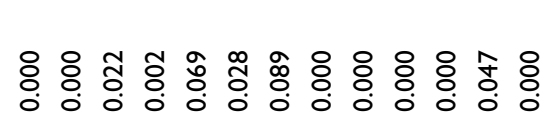 \\
\hline 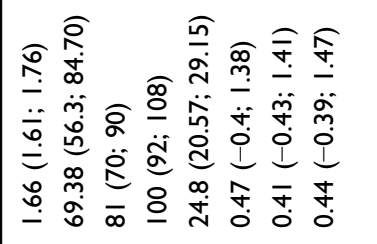 & 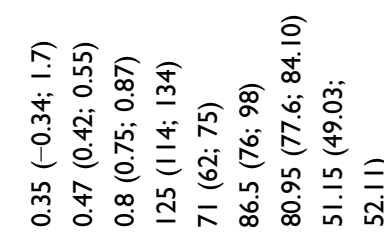 & 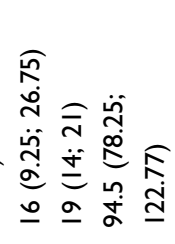 & 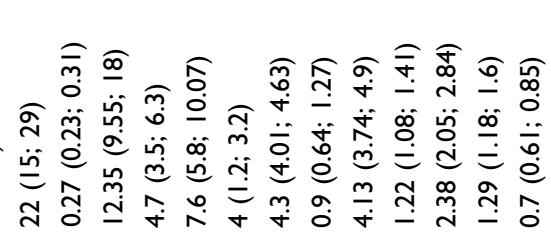 \\
\hline 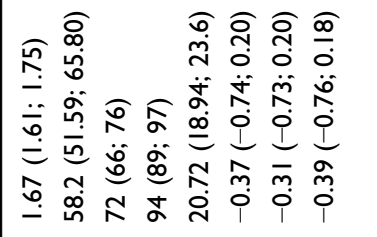 & 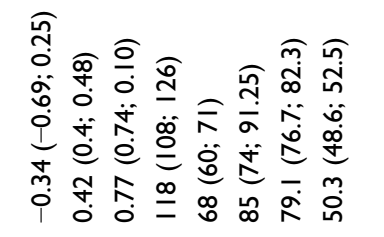 & 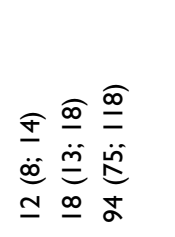 & 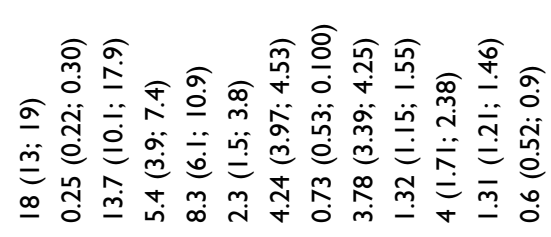 \\
\hline $\begin{array}{lllll}\infty & 0 \\
\stackrel{0}{\circ} & 0\end{array}$ & 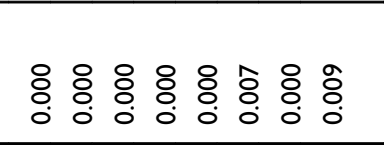 & 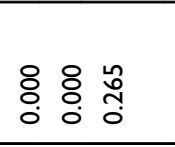 & 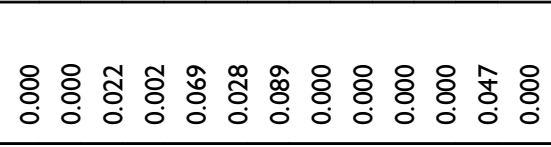 \\
\hline 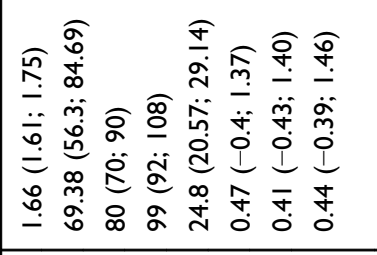 & 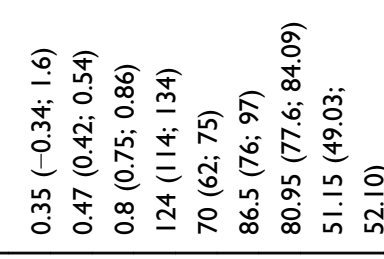 & 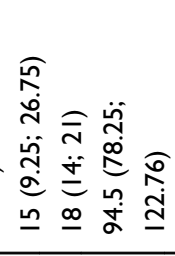 & 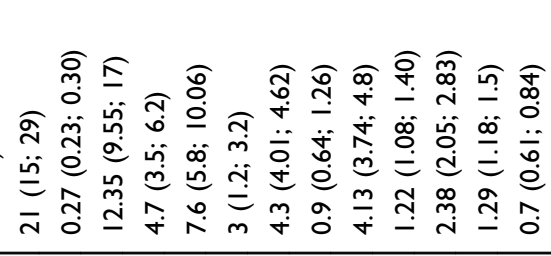 \\
\hline 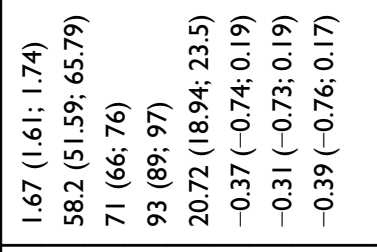 & 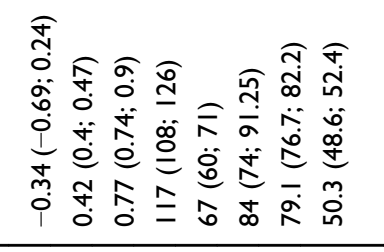 & 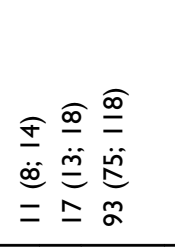 & 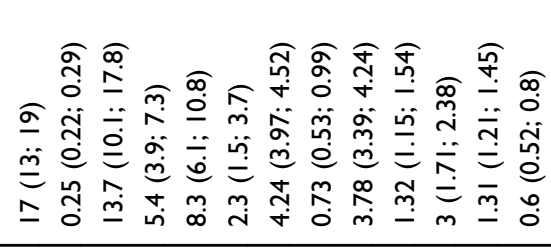 \\
\hline 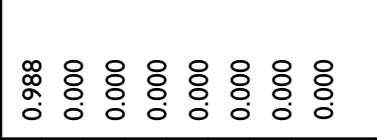 & 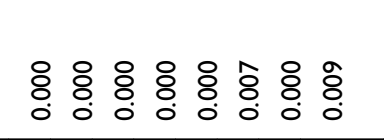 & 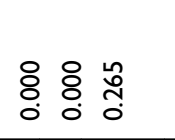 & 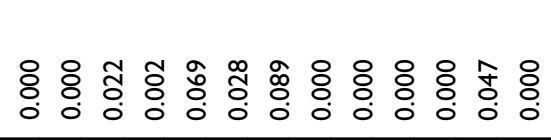 \\
\hline 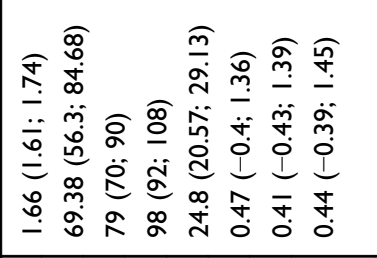 & 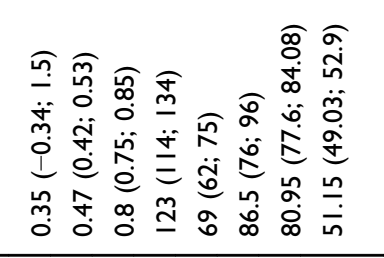 & 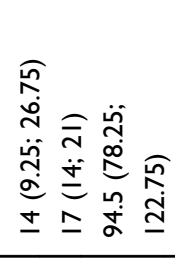 & 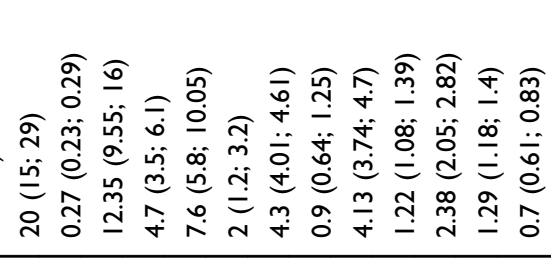 \\
\hline 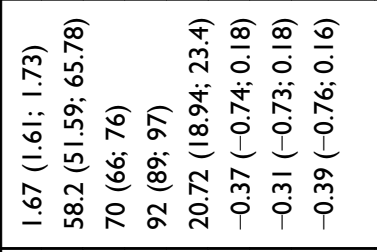 & 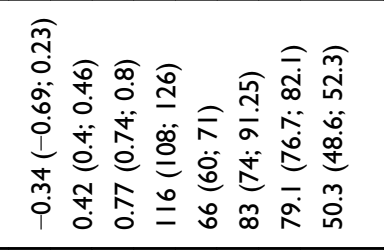 & 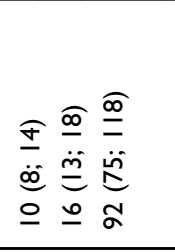 & 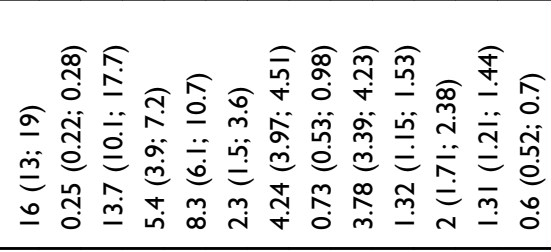 \\
\hline 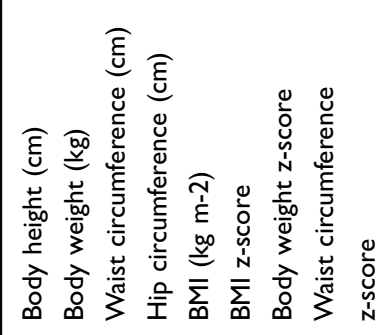 & 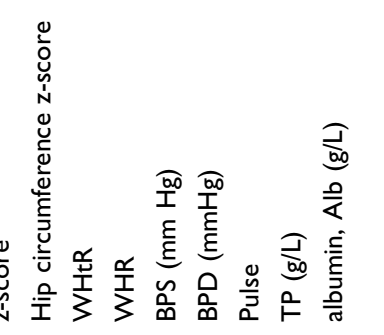 & 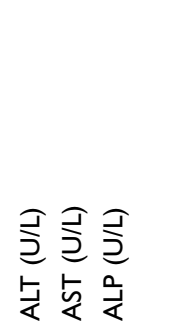 & 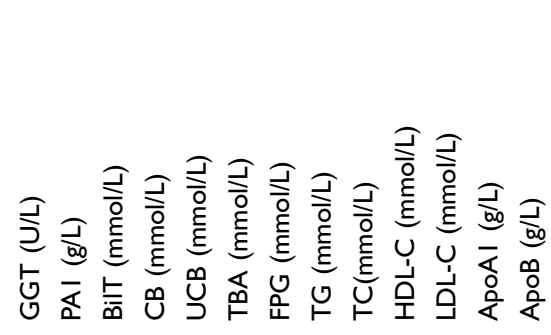 \\
\hline
\end{tabular}




\section{Publish your work in this journal}

Diabetes, Metabolic Syndrome and Obesity: Targets and Therapy is an international, peer-reviewed open-access journal committed to the rapid publication of the latest laboratory and clinical findings in the fields of diabetes, metabolic syndrome and obesity research. Original research, review, case reports, hypothesis formation, expert opinion and commentaries are all considered for publication. The manuscript management system is completely online and includes a very quick and fair peer-review system, which is all easy to use. Visit http://www.dovepress.com/testimonials.php to read real quotes from published authors.

Submit your manuscript here: https://www.dovepress.com/diabetes-metabolic-syndrome-and-obesity-targets-and-therapy-journal 